\title{
Unilateral brain damage effects on processing homonymous and polysemous words
}

\author{
Ekaterini Klepousniotou*, Shari R. Baum \\ McGill University, School of Communication Sciences and Disorders, 1266 Pine Ave. West Montreal, Que., Canada H3G 1 A8
}

Accepted 25 October 2004

Available online 10 December 2004

\begin{abstract}
Using an auditory semantic priming paradigm, the present study investigated the abilities of left-hemisphere-damaged (LHD) non-fluent aphasic, right-hemisphere-damaged (RHD) and normal control individuals to access, out of context, the multiple meanings of three types of ambiguous words, namely homonyms (e.g., "punch"), metonymies (e.g., "rabbit"), and metaphors (e.g., "star"). In addition, the study tested certain predictions of the "suppression deficit" and "coarse semantic coding" hypotheses that have been proposed to account for the linguistic deficits typically observed after RH damage. Homonymous, metonymous, and metaphorical words were used as primes followed after a short $(100 \mathrm{~ms})$ or a long $(1000 \mathrm{~ms})$ inter-stimulus interval (ISI) by dominant-meaningrelated, subordinate-meaning-related or unrelated target words. No significant group effects were found, and for both ISIs, dominant- and subordinate-related targets were facilitated relative to unrelated control targets for the homonymy and metonymy conditions. In contrast, for the metaphor condition, only targets related to the dominant meaning were facilitated. These findings provide only partial support for the "suppression deficit" hypothesis and no support for the "coarse semantic coding" hypothesis (as interpreted herein) indicating that patients with focal LH or RH damage can access the multiple meanings of ambiguous words and exhibit processing abilities comparable to those of older normal control subjects, at least at the single-word level.
\end{abstract}

(c) 2004 Elsevier Inc. All rights reserved.

Keywords: Semantic priming; Left-hemisphere damage; Right-hemisphere damage; Lexical ambiguity; Homonymy; Metonymy; Metaphor

\section{Introduction}

Lexical ambiguity, where a single word has more than one meaning, is very common in natural language. With respect to lexical semantics in general, an increasing amount of evidence suggests that both the left hemisphere ( $\mathrm{LH})$ and the right hemisphere $(\mathrm{RH})$ contribute to the comprehension of semantic relations. Although the left hemisphere is dominant for language processes, it is now acknowledged that the right hemisphere also possesses certain linguistic abilities. A review of the liter-

\footnotetext{
* Corresponding author. Fax: +1 5143988123.

E-mail address: ekaterini.klepousniotou@mail.mcgill.ca (E. Klepousniotou).
}

ature on language abilities after RH damage reveals abnormalities in the interpretation of lexical items (as well as larger linguistic units) that have multiple meanings (i.e., lexically ambiguous items), and an inability to revise an initial interpretation (Chiarello, 1991). However, the extent of the contribution of each hemisphere to the understanding of the different types of ambiguous words is still under investigation.

According to theoretical linguistics accounts, there is a distinction between two types of lexical ambiguity. The first type is homonymy, in which a lexical item carries two (or more) distinct and unrelated meanings, such as "pen " which means "a writing device" and "pen," which means "an enclosure." The other type of lexical ambiguity is polysemy, in which a single lexical item has 
several different but related senses, such as "rabbit," which refers to "the animal" and "the meat of that animal" (Cruse, 1986; Lyons, 1977). Polysemy is further divided into two types (Apresjan, 1974). The first type of polysemy is motivated by metaphor, and a relation of analogy is assumed to hold between the senses of the word. The basic sense of metaphorical polysemy is literal, whereas its secondary sense is figurative. For example, the ambiguous word "eye" has the literal basic sense "organ of the body" and the figurative secondary sense "hole in a needle." The other type of polysemy is motivated by metonymy, and the relation that is assumed to hold between the senses of the word is that of connectedness. According to Apresjan (1974), metonymically motivated polysemy respects the usual notion of polysemy, which is the ability of a word to have several distinct but related meanings. In metonymy, both the basic and the secondary senses are literal, as for example, the ambiguous word "rabbit" that has the literal basic sense referring to "the animal," and the literal secondary sense of "the meat of that animal."

Two criteria have been proposed for the distinction between homonymy and polysemy, namely the "etymological derivation of words" and the "relatedness/unrelatedness of meaning." However, there is not a clear dichotomy between homonymy and polysemy (Lyons, 1977), but rather a continuum from "pure" homonymy to "pure" polysemy, with metaphor being closest to homonymy, and metonymy being at the other extreme of the continuum, further away from homonymy (Apresjan, 1974).

Despite the aforementioned theoretical distinctions of lexical ambiguity, most work in psycholinguistics has concentrated on homonymy, while polysemous words have often been used interchangeably with homographs, homophones, or homonyms ${ }^{1}$ to test models and theories of lexical access and lexical ambiguity processing (Schreuder \& Flores d' Arcais, 1989; but cf. Klein \& Murphy, 2001; Rodd, Gaskell, \& MarslenWilson, 2002).

Most psycholinguistic studies on lexical ambiguity have focused on whether or not lexical access is an autonomous process (i.e., interactive versus modular) by

\footnotetext{
${ }^{1}$ Homographs, homophones, and homonyms refer to three subtypes of ambiguous words that have distinct, unrelated meanings. To clarify, homography is the case where two words have the same written form, but different pronunciation and meaning, such as "wound ${ }_{1}$ " which is the past tense of the verb "to wind," and "wound," which means "a sore/cut." Homophony is the case where two words are pronounced the same, but they have different written forms, as for example, "red" which refers to "a color," and "read" which is the past tense form of the verb "to read." Finally, homonymy is the case where both the pronunciation and written form of two words are the same, but they have distinct and unrelated meanings, as for example, "bank $k_{1}$ which means "a financial institution" and "bank ${ }_{2}$ " which means "the side of the river."
}

manipulating context and interstimulus intervals (ISIs) ${ }^{2}$ (e.g., Fodor, 1983; Swinney, 1991; also see Simpson, 1994 for a review). Examining the results of all the processing studies collectively, it seems that they point toward a compromise between pure selective and pure exhaustive access of meanings of ambiguous words. In particular, activation of all meanings of ambiguous (i.e., homonymous) words seems to occur initially, followed within $200 \mathrm{~ms}$ by selection of the contextually appropriate meaning. A neutral sentence context or a single word prime seems to have the same effect on the activation of the meanings of ambiguous words, namely to trigger exhaustive access, which, however, depends on frequency so that the more frequent meaning is more activated than the less frequent meaning (Simpson \& Burgess, 1985). In contrast, a highly constraining context may lead to selective access of the appropriate meaning only (e.g., Seidenberg, Tanenhaus, Leiman, \& Bienkowski, 1982; Swinney, 1979; Tabossi, 1988; Tanenhaus, Leiman, $\&$ Seidenberg, 1979). A hybrid model, known as the reordered access model, has been proposed to account for these findings (e.g., Duffy, Morris, \& Rayner, 1988; Rayner, Binder, \& Duffy, 1999; Rayner \& Frazier, 1989; Rayner, Pacht, \& Duffy, 1994). According to this model, although all meanings are activated simultaneously, the degree of activation depends on both frequency and type or strength of context.

Previous psycholinguistic studies have also shown that the interval between prime and target critically influences the processing of ambiguous words. In particular, it has been shown that the delay between prime and target (ISI) differentially affects the pattern of activation of the different meanings of ambiguous words (e.g., Burgess \& Simpson, 1988; Simpson \& Burgess, 1985; Simpson \& Krueger, 1991; Swinney, 1979). Time-course studies with young non-brain-damaged individuals have suggested that short intervals (up to $200 \mathrm{~ms}$ approximately) measure immediate activation processes, whereas measures taken at longer intervals (longer than $500 \mathrm{~ms}$ ) reflect later post-access selection processes (e.g., Simpson \& Burgess, 1985; Koivisto, 1998a).

As already mentioned, psycholinguistic studies to date have focused mainly on homonymy. With regard to polysemy, however, there is only limited evidence about representation and processing patterns. Nevertheless, recent studies show that homonymous and polysemous words are processed differentially and, thus, may be

\footnotetext{
${ }^{2}$ It should be noted that two terms exist in the literature to refer to the delay between primes and targets, namely ISI (interstimulus interval, that is the delay between the end of the prime and the beginning of the target) and SOA (stimulus onset asynchrony, that is the delay between the beginning of the prime and the beginning of the target). In the existing literature that is reviewed in this paper, some authors used measures of ISI, while others measured the SOA between primes and targets. Thus, when referring to these studies, we use the delay measures that the authors used in their experiments.
} 
stored differently in the mental lexicon. In particular, shorter fixation times (Frazier \& Rayner, 1990) and greater priming effects (Klepousniotou, 2002) have been found for metonymically polysemous words than homonymous words. Furthermore, there is evidence that ambiguous words with related meanings (i.e., metonymous words) are processed faster than unambiguous words, whereas ambiguous words with unrelated meanings (i.e., homonymous words) do not show such an advantage (Azuma \& Van Orden, 1997; Rodd et al., 2002). Finally, it has also been found that the various senses of polysemous words are interdependent (Williams, 1992; but cf. Klein \& Murphy, 2002), and it may not be possible to suppress them even in incongruent contexts (Williams, 1992). These findings may suggest differences in the representations of ambiguous words, depending on whether they have multiple meanings (i.e., homonymy) or multiple senses (i.e., polysemy) (but cf. Klein \& Murphy, 2001, 2002).

Turning to neurolinguistics, a great deal of research has focused on the neural substrates underlying the processing of ambiguous (i.e., homonymous) words. However, studies have not yet explored whether the theoretical and psychological differences found in normal populations among the three types of lexical ambiguity are affected differentially by brain damage. Most studies with brain-damaged populations (both LHD aphasic patients and RHD patients) on lexical ambiguity have only included homonymous words.

A series of early off-line studies has identified the linguistic deficits of patients with RHD with respect to lexical ambiguity (e.g., Brownell, 1988; Brownell, Potter, Michelow, \& Gardner, 1984; Brownell, Simpson, Bihrle, Potter, \& Gardner, 1990; Schmitzer, Strauss, \& DeMarco, 1997; Winner \& Gardner, 1977). Overall, these early offline studies have indicated that secondary or subordinate (i.e., non-literal, connotative) meanings are much less salient when the right hemisphere is dysfunctional. Based on these findings, as well as on later studies on lexical ambiguity processing by both normal and brain-damaged populations, two theories have been proposed to account for the lexical-semantic deficits observed in right-hemisphere-damaged (RHD) individuals, namely the "suppression deficit" and the "coarse semantic coding" hypotheses. According to the "suppression deficit" hypothesis, RHD patients' deviant performance with ambiguous words may be due to problems with suppressing interpretations that are initially activated, but eventually become irrelevant or incompatible with the context (Tompkins \& Lehman, 1998). The suppression mechanism operates less effectively in individuals with RHD than in normal individuals, and suppression function after RHD is hypothesized to correlate with comprehension (Tompkins \& Lehman, 1998). The large majority of investigations of the processing of lexical ambiguity by individuals with right-hemisphere damage (RHD) or left- hemisphere damage (LHD) have supported the "suppression deficit" hypothesis (e.g., Tompkins, Baumgaertner, Lehman, \& Fossett, 1997; Tompkins, Baumgaertner, Lehman, \& Fassbinder, 2000). In general, these studies have shown that RHD patients seem to be impaired in initially accessing context which leads them to an over-reliance on frequency (Grindrod \& Baum, 2003) and to ineffective use of contextual cues to eventually suppress inappropriate meanings (Tompkins et al., 2000). In addition, evidence for the "suppression deficit" hypothesis also comes from a lexical decision study using two ISIs (500 and $2000 \mathrm{~ms}$ ), in which Tompkins (1990) auditorily presented metaphorically polysemous target words (e.g., "sharp") that were preceded either by a prime that was an associate of the literal interpretation (e.g., "dull"), an associate of the metaphorical interpretation (e.g., "smart"), or an unrelated "neutral" word (e.g., "next"). She reported that individuals with RHD and LHD showed similar performance to normal control subjects except for absolute speed, supporting one tenet of the "suppression deficit" hypothesis, namely that individuals with RHD do not exhibit impairments in activating multiple word meanings. Responses to literal trials were faster than those to metaphorical trials, and both were faster than responses to neutral unrelated trials. Tompkins (1990) concluded that individuals with RHD did not have difficulty accessing the metaphoric aspects of word meaning. While interesting and suggestive, the conclusions were based on only three metaphorical polysemy stimulus pairs, and the critical target words were repeated at least 15 times in the experiment. Thus, the findings may be attributed to priming effects that occurred due to the repetitions of the target items. Furthermore, the critical prime words carried both a literal and a metaphorical meaning, possibly confounding the results.

The other major hypothesis concerning $\mathrm{RH}$ processing abilities has been proposed by Beeman (1993), and is known as the "coarse semantic coding" hypothesis. Beeman (1993, 1998) based his hypothesis on evidence from both normal participants and brain-damaged individuals which shows that the intact RH may sustain multiple interpretations of ambiguous words (Burgess \& Lund, 1998; Burgess \& Simpson, 1988) and distant semantic relations (Beeman et al., 1994; Chiarello, Burgess, Richards, \& Pollock, 1990), whereas the LH selects close associations and a single interpretation. According to the "coarse semantic coding" hypothesis, during word processing, the LH is most selective, strongly activating small semantic fields, while the RH diffusely activates large semantic fields (Beeman, 1998). Although such semantic processing makes the $\mathrm{RH}$ less effective for selecting the appropriate meaning of single words, it is more sensitive to semantic overlap and can maintain multiple word meanings. In contrast, the LH finely codes semantic input, so that a word strongly activates a limited subset of semantic features that are related to the 
appropriate meaning only. As a result, fine semantic coding makes the LH very efficient at selecting the frequent or contextually appropriate meaning for further processing. In the normal brain, both coarse and fine semantic coding presumably occur in parallel and interact at every stage of processing (Beeman et al., 1994).

The "coarse semantic coding" hypothesis was formulated based on the findings of a divided visual field study by Beeman et al. (1994) who, in a naming task with young healthy adults, visually presented unambiguous target words (e.g., "cut") preceded by either direct primes that show high feature overlap (i.e., three prime words, of which the first and third are "neutral," whereas the second is the direct prime that is very strongly related to the target; e.g., "none-scissors-whether"), summation primes that show less feature overlap (i.e., three prime words each weakly related to the target; e.g., "cry-foot-glass"), or unrelated primes (e.g., "dog-church-phone"). They found faster response times in the LH for targets preceded by direct primes than by summation primes or unrelated primes. In contrast, response times in the $\mathrm{RH}$ for targets preceded by either direct or summation primes were equivalent, and were faster than in the unrelated condition. These findings indicate a LH preference for closely related lexical items, since there was facilitation only when the prime was very strongly related to the target. On the other hand, the RH seems to have the ability to subserve a wider range of concepts, since facilitation effects were observed after both strongly and weakly related primes.

A number of studies using the divided visual field paradigm, as well as with brain-damaged populations, have been interpreted in light of the "coarse semantic coding" hypothesis. For example, in an ERP study with unambiguous words, Hagoort, Brown, and Swaab (1996) investigated the processing of very strongly related associative word pairs (e.g., "bread"-"butter"), more distant categorically related word pairs (e.g., "church"-“villa"), and unrelated word pairs (e.g., "hand"-"cherry") in normal control subjects, Broca's and Wernicke's aphasics, and individuals with RHD. Hagoort et al. (1996) found that the normal controls, the Broca's aphasics and the Wernicke's aphasics showed reduced N400 effects (of similar size) to related compared to unrelated target words for both associatively and categorically related pairs. In contrast, the RHD patients showed a dissociation between the associative and categorical word pairs, displaying a normal N400 effect for the associatively related word pairs, but no N400 effect (i.e., no reduction) for the categorically related word pairs (see also Chiarello et al., 1990 for similar results in a divided visual field study). Given that categorically related words are assumed to be more distantly related than associatively related words, the results of the study were interpreted as supporting the "coarse semantic coding hypothesis."

Most evidence in favour of the "coarse semantic coding" hypothesis, however, comes from divided visual field studies with young neurologically intact individuals that have been used to demonstrate hemispheric differences in lexical-semantic processing, using both unambiguous and ambiguous lexical items. Such studies have investigated the three types of semantic relations which are assumed to distinguish between closer and more distant relationships between words, namely "categorical only" words (e.g., "deer"-"pony"), "associated only" words (e.g., "bee"-"honey"), and "categorical and associated" words (e.g., "doctor"-"nurse") (Abernethy \& Coney, 1990, 1993, 1996; Chiarello et al., 1990; Chiarello \& Richards, 1992; Collins, 1999; Koivisto, 1997, 1998a). In general, with lateralized presentation of both prime and target, most of these studies showed no priming for "associated only" words (e.g., "bee"-"honey") in either hemisphere. Equivalent priming over visual fields was found for "categorical and associated" words (e.g., "doctor"-“nurse"). In addition, for "categorical only" words (e.g., "deer"-"pony") at short ISIs (<250 ms), greater priming was found in the $\mathrm{LH}$, whereas at long ISIs $(>500 \mathrm{~ms})$, greater priming was found in the RH. These findings suggest that the RH seems to be better at subserving weaker semantic relations than the LH, reflected in the prolonged activation of categorically related (i.e., more distantly related) words in the RH.

Subsequent studies, however, have shown that hemispheric differences in processing categorically or associatively related words can be manipulated by modifying the method of prime presentation (lateral or central), the response method (using the GO-NO GO technique) (e.g., Koivisto, 1998b, 2000) or the strength of the relation (e.g., Chiarello, Liu, Shears, Quan, \& Kacinik, 2003; Coney, 2002). In addition, similar results have been obtained in a number of studies investigating the importance of interhemispheric cooperation for the generation of alternative meanings of ambiguous words (e.g., Abernethy \& Coney, 1990, 1993; Collins, 2002), which suggest that the two hemispheres cooperate when generating alternate meanings of ambiguous words.

Nevertheless, a number of divided visual field studies with ambiguous words indicate that the cerebral hemispheres are differentially involved in the activation, selection, and suppression of ambiguous word meanings (e.g., Atchley, Keeney, \& Burgess, 1999; Burgess \& Simpson, 1988; Chiarello, Maxfield, \& Kahan, 1995). In particular, Burgess and Simpson (1988) first used the divided visual field paradigm to investigate the availability of dominant and subordinate meanings of ambiguous words in the $\mathrm{LH}$ and $\mathrm{RH}$, and the speed with which they may be retrieved. The investigators laterally presented target words associated with the dominant (e.g., "money") or subordinate meaning (e.g., "river") of ambiguous words (e.g., "bank"), after centrally presenting word primes, at SOAs of 35 or $750 \mathrm{~ms}$. Primes were either the related ambiguous word (e.g., "bank"), a neutral prime (e.g., "“-”), or an unrelated ambiguous word 
(e.g., "riddle"). Burgess and Simpson (1988) found immediate activation (i.e., at $35 \mathrm{~ms} \mathrm{SOA}$ ) of both dominant and subordinate meanings in the $\mathrm{LH}$, whereas only the dominant meaning was activated in the RH (see also Atchley, Burgess, \& Keeney, 1999 for similar results in the processing of multiple aspects of meaning of unambiguous words; Chiarello et al., 1995). Within $750 \mathrm{ms,}$ however, only the dominant meaning was activated in the LH, whereas both dominant and subordinate meanings were activated in the $\mathrm{RH}$, indicating that the $\mathrm{LH}$ eventually suppresses irrelevant meanings (in this case the subordinate ones), whereas the RH maintains activation for multiple meanings, perhaps by activating the subordinate meaning more slowly (see also Atchley, Burgess et al., 1999). These studies seem to suggest that, following the presentation of a single word prime, irrelevant meanings are suppressed in the $\mathrm{LH}$, whereas no suppression or limited suppression effects are observed in the RH (Faust \& Gernsbacher, 1996).

Similar results were also obtained in a study that investigated semantic priming for literal (e.g., "stinging"-"mosquito") and metaphoric (e.g., "stinging""insult") associates of words (i.e., associates of metaphorically polysemous words) at 200 and $800 \mathrm{~ms}$ SOAs (Anaki, Faust, \& Kravetz, 1998). At the $200 \mathrm{~ms}$ SOA, both literal and metaphorical targets were facilitated in the LH, whereas only metaphorical targets were facilitated in the RH. At the $800 \mathrm{~ms}$ SOA, however, only the literal targets were facilitated in the $\mathrm{LH}$, whereas facilitation remained for metaphorical targets in the RH. These findings again suggest that more closely related items are activated and maintained in the LH, while the RH subserves more distantly related words.

As discussed, a large corpus of studies has provided evidence in favour of either the "suppression deficit" or the "coarse semantic coding" hypotheses. However, the studies that supported the "suppression deficit" hypothesis included brain-damaged populations, while the studies that provided evidence in favour of the "coarse semantic coding" hypothesis mainly used the divided visual field methodology in young non-brain-damaged individuals. Another crucial difference between the studies that tested the two hypotheses is the fact that some of them used ambiguous lexical items whereas others used unambiguous words that exhibited different degrees of semantic relatedness among them. Given the methodological differences across the studies, it is difficult to compare their results and formulate a unified account of the lexical-semantic abilities of the $\mathrm{RH}$ and the deficits observed after RH damage. Thus, to date, experiments have been unable to unequivocally support one hypothesis over the other; that is, neither the "suppression deficit" nor the "coarse semantic coding" hypothesis has gathered clear support. The present study, which uses an auditory single-word priming paradigm, is designed in an effort to further address this issue, in particular by carefully controlling the types of lexical ambiguity under investigation.

\section{The present study}

By exploiting the theoretical linguistic distinction of lexical ambiguity into homonymy, metaphorical polysemy (i.e., metaphor), and metonymic polysemy (i.e., metonymy), it may be possible to contrast the predictions of the "suppression deficit" and the "coarse semantic coding" hypotheses. In homonymy, a lexical item carries two (or more) distinct and unrelated meanings. Therefore, there is no strong feature overlap between its meanings, and there is only a distant semantic relation. On the other hand, in metonymy, a single lexical item has several different but related senses. As a result, there is strong feature overlap between its senses, and a close semantic relation. Although Klein and Murphy (2001) provide evidence that, at least in some cases, the senses of polysemous words seem to be quite distinct, there are other studies (e.g., Frazier \& Rayner, 1990; Klepousniotou, 2002; Rodd et al., 2002; Williams, 1992) that show that there are cases (especially in metonymous words) where the senses are very closely related and seem to exhibit strong featural overlap. The present investigation exploits these types of metonymous words. Respecting the notion of a continuum from "pure" homonymy to "pure" polysemy (i.e., metonymy), metaphor seems to be somewhere between the two end-points. Although the multiple meanings may be somewhat related through analogy, they may not have strong feature overlap, and thus be closer to homonymy. Based on the nature of homonymy and metonymy, the "suppression deficit" and the "coarse semantic coding" hypotheses, in their strongest forms, make different predictions.

That is, the purest version of the "suppression deficit" hypothesis would predict that individuals with RHD should exhibit similar performance for all types of lexical ambiguity. Although psycholinguistic studies (e.g., Klepousniotou, 2002; Rodd et al., 2002) have shown differential processing for homonymous and polysemous words, the "suppression deficit" hypothesis does not make specific differential predictions depending on the type of lexical ambiguity. All three types (i.e., homonymy, metaphor, and metonymy) involve alternative meanings that must be suppressed, irrespective of whether they are literal or figurative and regardless of the strength of their interrelatedness. Thus, the purest version of the "suppression deficit" hypothesis would predict that individuals with RHD should be able initially to activate all meanings of each ambiguity type and at the longer delay be equally impaired at suppressing the alternative meanings of homonymous, metaphorical, and metonymous words. With respect to the individuals with LHD, the "suppression deficit" 
hypothesis does not make any specific predictions. However, one might extend the hypothesis to predict intact processing for all types of ambiguous words, as is also predicted for the older control participants.

It should be noted that the paradigm employed in the present study (i.e., single-word priming) can directly test only the first tenet of the "suppression deficit" hypothesis, namely whether there is access of multiple meanings initially (at the short ISI). Nevertheless, based on previous psycholinguistic studies with young healthy individuals (e.g., Simpson \& Burgess, 1985), it is also expected that at the long ISI $(1000 \mathrm{~ms})$ only dominant meanings will be facilitated, at least for the control subject group. For example, the aforementioned study has shown that facilitation for subordinate meanings is shorter-lived and usually decays at longer ISIs in the absence of biasing context (e.g., Simpson \& Burgess, 1985). Thus, the paradigm used in the present study could also indirectly tap the second tenet of the "suppression deficit" hypothesis, namely whether there is decay of subordinate meanings at the longer ISI for the control subject group, but not for the RHD participants. Although the "suppression deficit" hypothesis involves appreciation of context, it is also conceivable that, in the absence of context, one meaning (typically the subordinate) is suppressed or decays, so that there are no interference effects for the control subjects at the longer ISI. In contrast, individuals with RHD should exhibit prolonged facilitation of subordinate meanings, leading to the interference effects described by Tompkins et al. (1997, 2000). Despite the fact that for a true indication of suppression, lexical decisions on the unselected/subordinate meaning would have to be slower than on the unrelated condition, the "suppression deficit" hypothesis does not explicitly predict such differential patterns of results, leaving open the possibility that meaning suppression and meaning decay, which may in fact rely on different cognitive mechanisms, lead to similar response patterns (see Tompkins et al., 1997, 2000).

On the other hand, the "coarse semantic coding" hypothesis in its purest version would predict differential performance depending on the type of ambiguity the lexical items exhibit. In homonymy, the alternative meanings are unrelated and there is very weak feature overlap, whereas in polysemy, and in metonymic polysemy in particular, the alternative senses are interrelated and there is strong feature overlap. Since the RH processes semantically distant relationships, while the LH processes close semantic relationships, individuals with RHD should be differentially impaired at accessing alternative meanings of homonymous and possibly metaphorical words, but not of metonymous words.

In addition, given the nature of the "coarse semantic coding" hypothesis, it allows us to make predictions about the performance of the LHD non-fluent aphasic patients as well. In principle, since the $\mathrm{RH}$ processes both dominant and subordinate meanings (with certain differences in the time-course of activation) (e.g., Burgess \& Simpson, 1988; Chiarello et al., 1995), it could be argued that LHD non-fluent aphasic patients should not be impaired at accessing alternative meanings of ambiguous words. However, previous studies with LHD nonfluent aphasic patients (e.g., Milberg \& Blumstein, 1981; Milberg, Blumstein, \& Dworetzky, 1987) have shown that they exhibit impairments in meaning activation for ambiguous words. Thus, based on the assumptions of the purest version of the "coarse semantic coding" hypothesis and the results of previous studies with LHD non-fluent aphasic patients, it is predicted that, in contrast to the performance of the RHD patients, LHD individuals should be differentially impaired at accessing metonymous words that presumably are in the realm of the LH. Furthermore, it is conceivable that LHD patients would also be impaired accessing the basic or dominant meanings (that are presumably stored in the left hemisphere), but not the alternative meanings (that are assumed to be in the domain of the right hemisphere), of homonymous and possibly metaphorical words.

To start investigating the effects of the strength of the semantic relations that hold between the different meanings or the different senses of ambiguous words, and test the "suppression deficit" and the "coarse semantic coding" hypotheses, an auditory single-word priming study was conducted. Three factors were manipulated: (1) lesion site to test for hemispheric involvement in the processing of the different types of ambiguous words; (2) type of ambiguity (i.e., homonymy, metaphor, and metonymy) to test the effects of the strength of semantic relations; and (3) length of inter-stimulus interval (ISI) to investigate the time-course of activation.

\section{Method}

\subsection{Subjects}

Three groups of subjects participated in the present study: a group of 10 LHD non-fluent aphasic individuals (diagnosed according to results of the BDAE, see below), a group of 8 RHD individuals and a group of 10 normal control individuals matched in mean age to the two brain-damaged groups. Based on self-reports, all participants were right-handed (no familial handedness information was available). In addition, all subjects were native speakers of English with hearing within normal limits for their age, as attested by audiometric screening at $<35 \mathrm{~dB} \mathrm{HL}$ at the speech frequencies of $0.5,1.0$, and $2.0 \mathrm{kHz}$.

Brain-damaged patients were recruited from a number of institutions in the Montreal area, and they had all suffered a single unilateral cerebrovascular accident, 
confirmed by Computerized Axial Tomography (CT) or Magnetic Resonance Imaging (MRI) scans. The cerebrovascular accidents were due to hemorrhagic or ischemic infarcts. Radiological reports of CT and/or MRI scans as well as neurological reports determined the lesion sites. Most brain-damaged individuals had motor deficits on the contralateral side to their lesions at the time of the infarct onset. The presence of multiple infarcts, a history of drug or alcohol abuse, or a history of psychiatric and/or neurological disorders constituted criteria for initial exclusion. The brain-damaged patients were at least 6 months post-onset of stroke at the time of testing, and the two brain-damaged groups did not significantly differ in the number of months post-onset $[F(1,16)=0.213, p=.65]$.
Information about the etiology and lesion site of the brain-damaged individuals is provided in Tables 1 and 2 . Based on the CT/MRI scans and the neurological reports, five of the eight RHD patients [R03, R05, R06, $\mathrm{R} 07$, and R08] had a lesion that involved the territory of the right lateral cerebral cortex that is supplied with blood by the middle cerebral artery (MCA) (see Table 2). The other three patients [R01, R02, and R04] had primarily subcortical lesions involving the right cerebral hemisphere. In summary, the present group of RHD patients had unselected RH lesions (either cortical or subcortical) affecting the function of the right cerebral hemisphere. With regard to the LHD non-fluent aphasic patients, as can be seen in Table 1, they had lesions resulting from infarcts in the territory of the left middle

Table 1

Background information of non-fluent aphasic (LHD) individuals

\begin{tabular}{|c|c|c|c|c|c|c|c|c|c|c|}
\hline \multirow[t]{2}{*}{ Patient } & \multirow{2}{*}{$\begin{array}{l}\text { Age } \\
\text { (years) }\end{array}$} & \multirow{2}{*}{$\begin{array}{l}\text { Education }^{\mathrm{a}} \\
\text { (years) }\end{array}$} & \multirow[t]{2}{*}{ Sex } & \multirow[t]{2}{*}{ Etiology } & \multirow[t]{2}{*}{ Lesion site ${ }^{b}$} & \multirow[t]{2}{*}{ MPO } & \multirow{2}{*}{$\begin{array}{l}\mathrm{BDAE} \\
\mathrm{AC}(\%)\end{array}$} & \multirow{2}{*}{$\begin{array}{l}\mathrm{BNT} \\
(/ 60)\end{array}$} & \multicolumn{2}{|l|}{ PAL } \\
\hline & & & & & & & & & SWPM (/32) & $\operatorname{ASC}(/ 40)$ \\
\hline L01 & 70 & 9 & $\mathrm{~F}$ & $\mathrm{H}$ & L fronto-temporo-parietal & 109 & 60 & 15 & 32 & 27 \\
\hline L02 & 74 & 12 & $\mathrm{~F}$ & I & $\mathrm{L}$ parietal & 110 & 88.75 & 53 & 32 & 40 \\
\hline L03 & 58 & 11 & $\mathrm{~F}$ & I & L MCA territory & 42 & 50 & 35 & 32 & 30 \\
\hline L04 & 57 & 10 & M & I & $\mathrm{L}$ carotid artery ischemia & 32 & 84 & 37 & 32 & 37 \\
\hline L05 & 82 & 9 & M & $\mathrm{H}$ & L frontal (precentral) & 86 & 88.75 & 55 & 30 & 34 \\
\hline L06 & 50 & 14 & $\mathrm{~F}$ & I & $\begin{array}{l}\text { L fronto-parietal (with } \\
\text { subcortical extensions) }\end{array}$ & 131 & 87.5 & 43 & 31 & 36 \\
\hline L07 & 79 & 16 & $\mathrm{~F}$ & I & $\mathrm{L}$ parietal & 17 & 63.3 & $\mathrm{n} / \mathrm{a}$ & 31 & 32 \\
\hline L08 & 54 & 14 & M & I & $\mathrm{L}$ parietal & 178 & 90 & 45 & 32 & 32 \\
\hline L09 & 60 & 20 & M & I & L cortical/subcortical & 41 & 30 & $\mathrm{n} / \mathrm{a}$ & 31 & 31 \\
\hline L10 & 69 & 12 & $\mathrm{~F}$ & I & L fronto-parietal & 86 & 82.5 & 18 & 32 & 30 \\
\hline Mean & 65.3 & 12.7 & & & & 83.2 & 72.5 & 37.6 & 31.5 & 32.9 \\
\hline$S D$ & 11.0 & 3.4 & & & & 50.7 & 20.7 & 14.8 & 0.7 & 3.9 \\
\hline
\end{tabular}

Note. L, left hemisphere; $\mathrm{H}$, hemorrhagic infarct; I, ischemic infarct; MCA, middle cerebral artery; MPO, months post-onset; BDAE, Boston Diagnostic Aphasia Examination; AC, Auditory Comprehension (percentage score); BNT, Boston Naming Test (maximum score, 60); PAL, Psycholinguistic Assessment of Language; SWPM, Spoken Word-Picture Matching (maximum score, 32); ASC, Auditory Sentence Comprehension (maximum score, 40); n/a, not available.

a Best estimated conversion into years, based on information from subject (e.g., 2 years college, high school).

${ }^{\mathrm{b}}$ Established on the basis of CT/MRI scans and/or neurological reports.

Table 2

Background information of right-hemisphere-damaged (RHD) individuals

\begin{tabular}{|c|c|c|c|c|c|c|c|c|c|}
\hline \multirow[t]{2}{*}{ Patient } & \multirow{2}{*}{$\begin{array}{l}\text { Age } \\
\text { (years) }\end{array}$} & \multirow{2}{*}{$\begin{array}{l}\text { Education }{ }^{\mathrm{a}} \\
\text { (years) }\end{array}$} & \multirow[t]{2}{*}{ Sex } & \multirow[t]{2}{*}{ Etiology } & \multirow[t]{2}{*}{ Lesion Site $^{b}$} & \multirow[t]{2}{*}{ MPO } & \multicolumn{2}{|c|}{ TLC-E adapted } & \multirow{2}{*}{$\begin{array}{l}\text { PAL } \\
\text { ASC (/40) }\end{array}$} \\
\hline & & & & & & & Fig $(/ 10)$ & $\operatorname{Inf}(/ 10)$ & \\
\hline R01 & 61 & 13 & $\mathrm{~F}$ & $\mathrm{H}$ & R PCoA territory & 146 & 8 & 10 & 40 \\
\hline R02 & 72 & 14 & M & $\mathrm{H}$ & $\mathrm{R}$ thalamus & 66 & 6 & 7 & 37 \\
\hline R03 & 81 & 11 & M & I & R MCA (fronto-temporo-parietal) & 59 & 7 & 7 & 37 \\
\hline R04 & 68 & 13 & $\mathrm{~F}$ & $\mathrm{H}$ & $\mathrm{R}$ internal capsule/basal ganglia & 86 & 5 & 9 & 39 \\
\hline R05 & 44 & 9 & $\mathrm{~F}$ & I & R MCA territory & 65 & 6 & 4 & 36 \\
\hline R06 & 36 & 13 & $\mathrm{~F}$ & I & R MCA (parietal) & 83 & 9 & 10 & 38 \\
\hline R07 & 65 & 12 & M & I & R MCA territory & 18 & 7 & 6 & 35 \\
\hline R08 & 90 & 11 & M & $\mathrm{H}$ & R MCA territory & 64 & 7 & 6 & 38 \\
\hline Mean & 64.6 & 12.0 & & & & 73.4 & 6.9 & 7.4 & 37.5 \\
\hline$S D$ & 17.9 & 1.6 & & & & 35.9 & 1.2 & 2.1 & 1.6 \\
\hline
\end{tabular}

Note. R, right hemisphere; H, hemorrhagic infarct; I, ischemic infarct; MCA, middle cerebral artery; PCoA, posterior communicating artery; MPO, months post-onset; TLC-E, Test of Language Competence-Expanded Edition; Fig, figurative language (maximum score, 10); Inf, inferences (maximum score, 10); PAL, Psycholinguistic Assessment of Language; ASC, Auditory Sentence Comprehension (maximum score, 40).

${ }^{a}$ Best estimated conversion into years, based on information from subject (e.g., 2 years college, high school).

${ }^{\mathrm{b}}$ Established on the basis of CT/MRI scan and/or neurological reports. 
cerebral artery affecting the function of the left lateral cerebral cortex.

A series of screening and diagnostic tests were administered to the brain-damaged patients. The diagnostic tests differed (in part) across the groups given that left and right hemisphere lesions typically lead to different types of impairments. In particular, the diagnosis of type of aphasia exhibited by the LHD patients was determined by results of the Boston Diagnostic Aphasia Examination (BDAE) (Goodglass, Kaplan, \& Barresi, 2001). On the other hand, RHD patients do not typically exhibit aphasic-like linguistic impairments. However, they do exhibit more subtle linguistic impairments in making inferences and comprehending figurative language. Therefore, RHD patients were subjected to a test battery adapted from the Test of Language CompetenceExpanded Edition (TLC-E) (Wiig \& Secord, 1987) to examine inferencing and figurative language abilities; they were also tested on sections of an Emotional Prosody Battery. As can be seen in Table 2, RHD patients indeed exhibited problems with inferencing and figurative language typically observed in this subject population. Overall, these screening tests were used to ensure that the brain-damaged patients participating in the study had representative impairments typically observed in LHD non-fluent aphasic and RHD individuals, respectively, and that their overall profiles fit the typical profile of LHD non-fluent aphasic patients and RHD patients, respectively, although this may not be necessarily reflected in the particular scores reported here.

In addition, both groups of brain-damaged individuals were administered further tests to ensure that they had adequate speech and language skills necessary for their participation in the study, and in particular, adequate auditory comprehension of single words and simple sentences so that the task materials and instructions would be understood. It should be noted, however, that comprehension impairments associated with syntactically complex sentences or discourse-level passages were not grounds for exclusion. Therefore, both patient groups used in the study represented unselected brain-damaged populations in terms of comprehension. The additional tests included: the Bells test and sections (line crossing, letter cancellation, star cancellation, figure and shape copying, line bisection, and representational drawing) of the Behavioural Inattention Test (BIT) (Wilson, Cockburn, \& Halligan, 1987) to screen for visual neglect, an Auditory Digit Span test, as well as a series of tests to ensure speech and language skills including the Written Word-Picture Matching subtest, the Spoken Word-Picture Matching subtest, the Auditory Sentence Comprehension subtest from the Psycholinguistic Assessment of Language (PAL) (Caplan, 1992).

The normal control group was selected from volunteers in the Montreal area. They were matched as closely as possible to the two brain-damaged groups for mean age $(M=69.7, S D=3.7)$, sex and education level
( $M=13.4, S D=3.2)$ (see Table 3). Normal control subjects had no history of neurological and/or psychiatric illness, or speech-language disorders. All control subjects were screened with a series of neuropsychological tests to exclude the possibility of cognitive decline or dementia. These tests included the Boston Naming Test (BNT) (Kaplan, Goodglass, \& Weintraub, 1983), the Mini-Mental State Examination (MMSE) (Folstein, Folstein, \& McHugh, 1975), and the Logical Memory I (immediate recall) and II (delayed recall) subtests of the Wechsler Memory Scale-Revised (WMS-R) (Wechsler, 1987). Participants were excluded if they scored below criterion on two of the screening tests (e.g., below 26/32 on MMSE and below $70 \%$ on both Logical Memory I and II). The three participant groups did not differ significantly in terms of years of education $[F(2,25)=0.5043, p=.609]$, or age $[F(2,25)=0.5218, p=.599]$. A summary of neuroradiological, demographic, and language performance data for the LHD non-fluent aphasic and RHD individuals as well as for the normal control individuals is presented in Tables $1-3$, respectively.

\subsection{Materials}

Prime-target pairs representing three distinct types of lexical ambiguity were constructed in the following way. Eighteen of each of the three types of ambiguous words were selected as primes: (1) unbalanced homonymous words (e.g., "bank") [i.e., one meaning was more frequent (i.e., dominant) than the other meaning (i.e., subordinate)]; (2) metaphorical words (e.g., "mouth"); and (3) metonymous words (e.g., "rabbit").

Unbalanced homonymous words were chosen from standardized lists of ambiguous words (e.g., Durkin \& Manning, 1989; Gilhooly \& Logie, 1980; Nelson, McEvoy, Walling, \& Wheeler, 1980; Twilley, Dixon, Taylor, $\&$ Clark, 1994; Yates, 1978). The frequency of

Table 3

Background information of normal control individuals

\begin{tabular}{lllll}
\hline Subject & Age (years) & Education $^{\text {a }}$ (years) & Sex & BNT (/60) \\
\hline C01 & 70 & 9 & $\mathrm{M}$ & 57 \\
C02 & 68 & 18 & $\mathrm{~F}$ & $\mathrm{n} / \mathrm{a}$ \\
C03 & 66 & 11 & $\mathrm{M}$ & 47 \\
C04 & 68 & 13 & $\mathrm{~F}$ & 58 \\
C05 & 68 & 16 & $\mathrm{~F}$ & 48 \\
C06 & 66 & 13 & $\mathrm{~F}$ & 51 \\
C07 & 74 & 14 & $\mathrm{M}$ & 45 \\
C08 & 78 & 18 & $\mathrm{~F}$ & 55 \\
C09 & 69 & 9 & $\mathrm{M}$ & 51 \\
C10 & 70 & 13 & $\mathrm{~F}$ & 55 \\
Mean & 69.7 & 13.4 & & 51.9 \\
SD & 3.7 & 3.2 & & 4.6 \\
\hline
\end{tabular}

Note. C, control subjects; BNT, Boston Naming Test (maximum score, $60) ; \mathrm{n} / \mathrm{a}$, not available.

a Best estimated conversion into years, based on information from subject (e.g., 2 years college, high school). 
occurrence of the dominant meaning was never less than $63 \%$, and the frequency of occurrence of the subordinate meaning was never greater than $32 \%$. Overall, the dominant meaning had a mean frequency of occurrence of $77 \%$ (range: $63-93 \%$ ) and the subordinate meaning had a mean frequency of $15 \%$ (range: $2-32 \%$ ). The average frequency of occurrence of the homonymous words was 36 (Francis \& Kucera, 1982).

As there are no standardized lists of metonymous and metaphorical words, these were chosen to exhibit specific relations between their two senses as documented in the theoretical linguistics literature (e.g., Nunberg, 1979; Pustejovsky, 1995). To investigate the effects of a broader range of words with metonymic and metaphorical meaning extensions, as well as to control for repetition effects and semantic facilitation effects from an experimental stimulus to another, multiple types of metonymous and metaphorical words were included. In particular, metonymous words exhibited the following types of metonymic relations: 6 words with the count/mass relation (e.g., "rabbit"); 6 words with the container/containee relation (e.g., "bottle"); and 6 words with the figure/ground reversals relation (e.g., "cage"). The mean frequency of occurrence for the metonymous words was 26 (Francis \& Kucera, 1982). Similarly, metaphorical words exhibited three types of metaphorical relations, namely 6 body part/object words (e.g., "mouth"), 6 ani$\mathrm{mal} /$ human characteristic words (e.g., "fox"), and 6 object/human characteristic words (e.g., "star"). The average frequency of occurrence of the metaphorical words was 30 (Francis \& Kucera, 1982). The classification of all stimuli as homonymous, metonymous or metaphorical was also verified by consulting standard dictionaries (see also Rodd et al., 2002). All such dictionaries respect the distinction between homonymy and polysemy by listing the different meanings of homonymous words as separate entries, whereas the different senses of metonymous and metaphorical words are listed within a single entry. In addition, all standard dictionaries respect sense dominance by listing the central or dominant sense of metonymous and metaphorical words first and then providing the extended or subordinate senses. Finally, all ambiguous prime words were matched for frequency of occurrence (Francis \& Kucera, 1982), syllable length, concreteness, and grammatical category (see Appendix).

Four types of auditory targets were used: (1) words related to one meaning of the ambiguous word primes; (2) words related to the other meaning of the ambiguous word primes; (3) control words unrelated to the ambiguous word primes; and (4) legal non-words. Target words were matched for frequency of occurrence, syllable length, and concreteness. Target non-words were constructed respecting the phonotactic rules of English.
Word associates for the homonymous, metonymous, and metaphorical words with the animal/human characteristic relation were obtained from a standardized list of word association norms (Nelson, McEvoy, \& Schreiber, 1998). For the metaphorical words exhibiting body part/ object relations (e.g., "mouth") and object/human characteristic relations (e.g., "star"), which did not appear in the word association norms, a word association study was administered. A (different) group of 30 healthy young adults was asked to generate the first three words associated with a given ambiguous word. Two sentences were constructed for each ambiguous word that clarified the intended meaning (either the dominant or the subordinate). The ambiguous word always appeared in sentence-final position and was underlined. The participants were asked to read the sentences carefully and provide the first three words they thought of that were related to the underlined ambiguous word and the specific meaning it conveyed in the given sentence. To avoid repetition of the ambiguous words, two lists of sentences were constructed that were administered with an interval of 10 days. Responses were grouped according to the general meaning they conveyed (e.g., for the metaphorically polysemous word "nucleus," the first meaning group was "chemistry" and the second meaning group was "basis of a community"). Only ambiguous words for which word associates for both their meanings were given by more than $80 \%$ of the participants were used in the priming study.

In the experiment, each word prime was followed either by a target word related to its dominant meaning, a target word related to its other (subordinate) meaning, an unrelated control target word, or a non-word. Overall, there were 54 experimental prime words, 162 target words and an equal number of target non-words. Nonwords were presented following prime words that had the same characteristics as the experimental prime words (e.g., ambiguity type, syllable length, grammatical category, etc.), but were not part of the experimental prime word groups. All stimuli were recorded by a female native speaker of English, digitized at a rate of $20 \mathrm{k}$ samples/second and low pass filtered at $9 \mathrm{kHz}$ using the Brown Lab Interactive Speech System (BLISS) software (Mertus, 2000).

The interval (ISI) between the offset of the prime word and the onset of the target item was manipulated to investigate the time-course of activation. Based on previous studies (e.g., Anaki et al., 1998; Burgess \& Simpson, 1988; Tompkins et al., 2000), a short (100 ms) and a long $(1000 \mathrm{~ms})$ interval were chosen to explore the automatic versus the more controlled processes of meaning activation (and suppression). Each trial consisted of the auditory presentation of an ambiguous word prime and a target (either word or non-word). All trials were presented at both ISIs in two separate lists. Each list contained 54 ambiguous word primes with dominant 
meaning related word targets, 54 ambiguous word primes with subordinate meaning related word targets, 54 ambiguous word primes with unrelated control word targets, and 162 filler ambiguous word primes with nonword targets (for a total of 324 trials). Thus, within each list, the primes were repeated three times but the targets were only presented once. Trials within each list were presented in a fixed pseudo-random order so that identical primes were at least 20 trials apart.

\subsection{Procedure}

All participants were tested in two sessions (one per ISI). The testing sessions lasted approximately $35 \mathrm{~min}$ for the short ISI $(100 \mathrm{~ms})$, and $40 \mathrm{~min}$ for the long ISI $(1000 \mathrm{~ms})$. The order of presentation of the two ISIs was counterbalanced across subjects. Test sessions were administered with an interval of 1 week between them to avoid any carry-over repetition effects.

Participants were tested individually, seated in a comfortable position. They were wearing headphones and the volume was adjusted to their preference. Each trial began with the auditory presentation of a word prime through the headphones. At 100 or $1000 \mathrm{~ms}$ after the offset of the word prime, an auditory target was presented for lexical decision. Participants were told that the first word they heard was always a real word in English, and they would have to make lexical decisions only about the second word. They were instructed to respond as accurately and as quickly as possible on a response box located in front of them (using their currently dominant hand) by pressing the YES key if they thought the second word was a real word in English, and the NO key if they thought it was a non-word. Reaction times (in $\mathrm{ms}$ ) and accuracy rate were recorded by the computer.

Reaction times were recorded from the onset of the target until the participant responded. If the participant did not respond within $3900 \mathrm{~ms}$, the trial was recorded as a non-response, and the next trial was presented. The inter-trial interval was set at $4000 \mathrm{~ms}$. A practice session of six trials preceded the presentation of the actual experiment. If the participants did not understand the task, the practice session was repeated and oral examples were given until it was clear what the task required.

\section{Results}

Error rates for lexical decision responses were first examined. For each subject, error rates were calculated for each ISI condition separately. A cutoff accuracy rate of $67 \%$ was used, so that the data of any subject who made more than $33 \%$ errors were removed from further analysis. No subject reached the cutoff point; thus, all data were used in the statistical analyses. For the short
ISI (100 ms), NC subjects made a total of $1 \%$ real word errors, LHD non-fluent aphasic subjects made a total of $4.2 \%$ real word errors, and RHD subjects made a total of $2.6 \%$ real word errors. For the long ISI $(1000 \mathrm{~ms}), \mathrm{NC}$ subjects made a total of $1.7 \%$ real word errors, LHD non-fluent aphasic subjects made a total of $5.9 \%$ real word errors, and RHD subjects made a total of $2.8 \%$ real word errors. It must be noted that a substantial proportion of errors for the LHD group in the long ISI is attributable to a single subject (L07) who was responsible for $1.9 \%$ of the errors. The distribution of errors did not differ statistically among the subject groups for either the short $[F(8,100)=0.655, p=.729]$ or the long $[F(8,100)=1.811, p=.083]$ ISI.

As far as the non-word trials are concerned, for the short ISI $(100 \mathrm{~ms})$, NC subjects made a total of 3.9\% nonword errors, LHD non-fluent aphasic subjects made a total of $6.2 \%$ non-word errors, and RHD subjects made a total of $11.2 \%$ non-word errors. For the long ISI $(1000 \mathrm{~ms}), \mathrm{NC}$ subjects made a total of $4 \%$ non-word errors, LHD non-fluent aphasic subjects made a total of $5 \%$ non-word errors, and RHD subjects made a total of $10.7 \%$ non-word errors. The three subject groups did not differ statistically in terms of the number of errors they made to non-word trials for either the short $[F(2,25)=$ $1.968, p=.16]$ or the long $[F(2,25)=2.263, p=.12]$ ISI.

Given that accuracy did not vary as a function of any of the experimental conditions in the study, the discussion will be restricted to the results of the reaction time (RT) data. Only correct responses to word targets were analyzed. Prior to statistical analysis, errors, and outliers ( \pm 2 standard deviations from each subject's mean per condition) were removed. Due to the fact that the three groups had an unequal number of subjects, the reaction time data were normalized using a $\log$ transformation (Stevens, 1996). The log transformed data were then subjected to 3 (Group) $\times 3$ (Ambiguity type) $\times 3$ (Target type) repeated measures analyses of variance (ANOVA) for subjects $\left(F_{1}\right)$ and items $\left(F_{2}\right)$ for each ISI separately.

\section{1. $100 \mathrm{~ms}$ ISI condition}

For the short ISI $(100 \mathrm{~ms})$, errors, and outliers $( \pm 2$ standard deviations) comprised $7.7 \%$ of the data for the NC subjects, $8.9 \%$ of the data for the LHD non-fluent aphasic subjects, and $7.8 \%$ of the data for the RHD subjects.

The Group (NC, LHD, and RHD) $\times$ Ambiguity type (Homonymy, Metonymy, and Metaphor) $\times$ Target type (dominant-related, subordinate-related, and unrelated) ANOVA revealed significant main effects of Target type $\left[F_{1}(2,50)=96.248, \quad p<.001 ; \quad F_{2}(2,152)=18.8, p<.001\right]$ and Group (by items only) $\left[F_{1}(2,25)=0.982, p=.388\right.$; $\left.F_{2}(2,304)=56.5, p<.001\right]$. There was also a significant Ambiguity type $\times$ Target type interaction $\left[F_{1}(4,100)=\right.$ $9.726, p<.001 ; F_{2}(4,152)=1.8, p=.124$ ] (by subjects 
only). Post hoc comparisons using the Newman-Keuls test $(\mathrm{p}<.05)$ were used to further explore the Ambiguity type $\times$ Target type interaction. Across subject groups, RTs to both dominant- and subordinate-related targets were significantly faster than to unrelated targets for the homonymy and metonymy conditions (see Fig. 1). On the other hand, for the metaphor condition, only targets related to the dominant meaning were facilitated (see Fig. 1).

We then proceeded to inspect the individual data in an attempt to investigate whether the observed group effects were indeed representative of the performance of individual subjects. For homonymy, the group pattern of performance was evident in $70 \%$ of NC and LHD individuals and $90 \%$ of RHD patients. For metonymy, the pattern of facilitation was shown by $100 \%$ of NC, $90 \%$ of LHD, and $75 \%$ of RHD individuals. Therefore, for both homonymy and metonymy, individual performance within each group paralleled group performance. Inspection of the individual data in the metaphor condition revealed that individual performance was more variable, as the group pattern of facilitation for dominant meanings alone was observed in only $40 \%$ of $\mathrm{NC}$ and $50 \%$ of LHD and RHD individuals; in contrast, $60 \%$ of $\mathrm{NC}$, $50 \%$ of LHD, and $35 \%$ of RHD showed facilitation for both dominant- and subordinate-related meanings, while $15 \%$ of RHD individuals did not show facilitation for either dominant- or subordinate-related meanings (which, given the small number of subjects, actually pertains to only one individual in the RHD group). However, there were no obvious characteristics that differentiated those individuals who conformed to the group pattern from the others who did not, in any subject group.

\section{2. $1000 \mathrm{~ms}$ ISI condition}

For the long ISI $(1000 \mathrm{~ms})$, errors and outliers $( \pm 2$ standard deviations) comprised $6.9 \%$ of the data for the NC subjects, $10.1 \%$ of the data for the LHD non-fluent aphasic subjects, and $8.4 \%$ of the data for the RHD subjects.

The Group (NC, LHD, and RHD) $\times$ Ambiguity type (Homonymy, Metonymy, and Metaphor) $\times$ Target type (dominant-related, subordinate-related, and unrelated) ANOVA revealed significant main effects of Target type $\left[F_{1}(2,50)=59.53, p<.001\right.$; $\left.F_{2}(2,153)=14.6, p<.001\right]$ and Group (by items only) $\left[F_{1}(2,25)=2.72, p=.085 ; F_{2}(2,306)=185.2, p<.001\right]$. Furthermore, the Ambiguity type $\times$ Target type interaction was significant for subjects $\left[F_{1}(4,100)=5.73\right.$, $p<.001 ; F_{2}(4,153)=0.6, p=.689$ ], but there was no interaction with Group. Post hoc comparisons using the Newman-Keuls test $(p<.05)$ were used to explore further the Ambiguity type $\times$ Target type interaction. As in the short ISI condition, dominant- and subordinate-
A

Normal Controls at $100 \mathrm{~ms}$

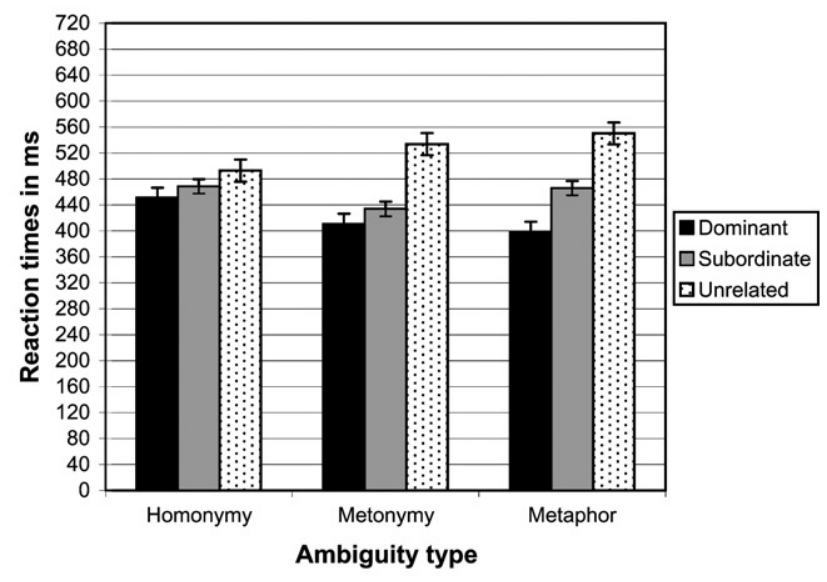

B

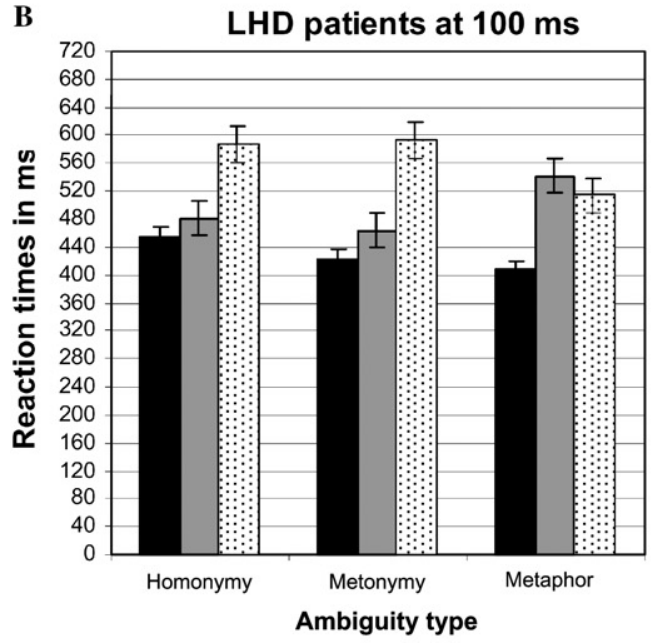

Dominant $\square$ Subordinate Qunrelated

C
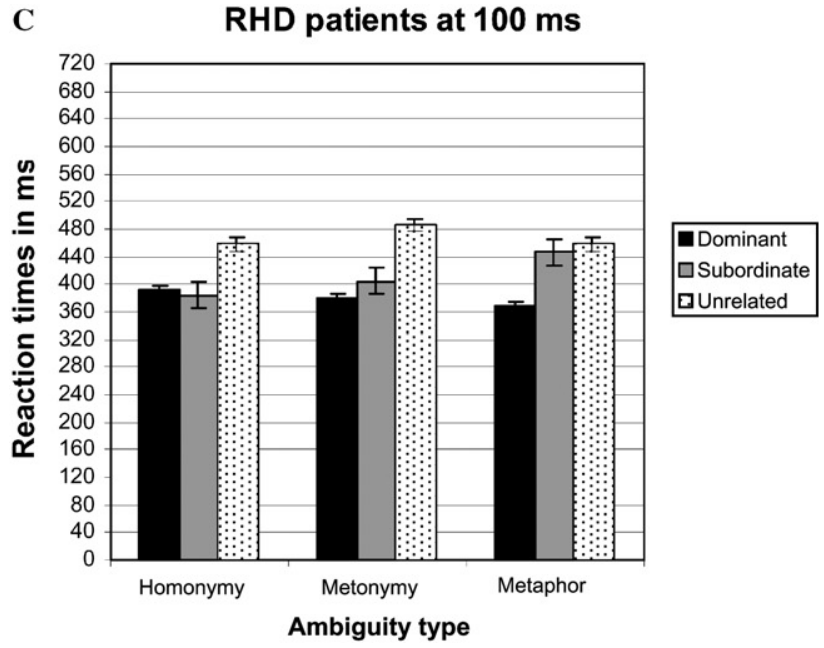

Fig. 1. Mean reaction times (and standard error) for all Groups at $100 \mathrm{~ms}$ ISI for dominant related word targets (Dominant), subordinate related word targets (Subordinate), and control unrelated words targets (Unrelated) for each ambiguity type (Homonymy, Metonymy, and Metaphor).

related targets were processed significantly faster than unrelated targets for the homonymy and metonymy conditions for the three subject groups (see Fig. 2). 
In contrast, for the metaphor condition, only targets related to the primary meaning were facilitated (see Fig. 2).

As in the short ISI condition, we inspected the individual data in an attempt to investigate whether the
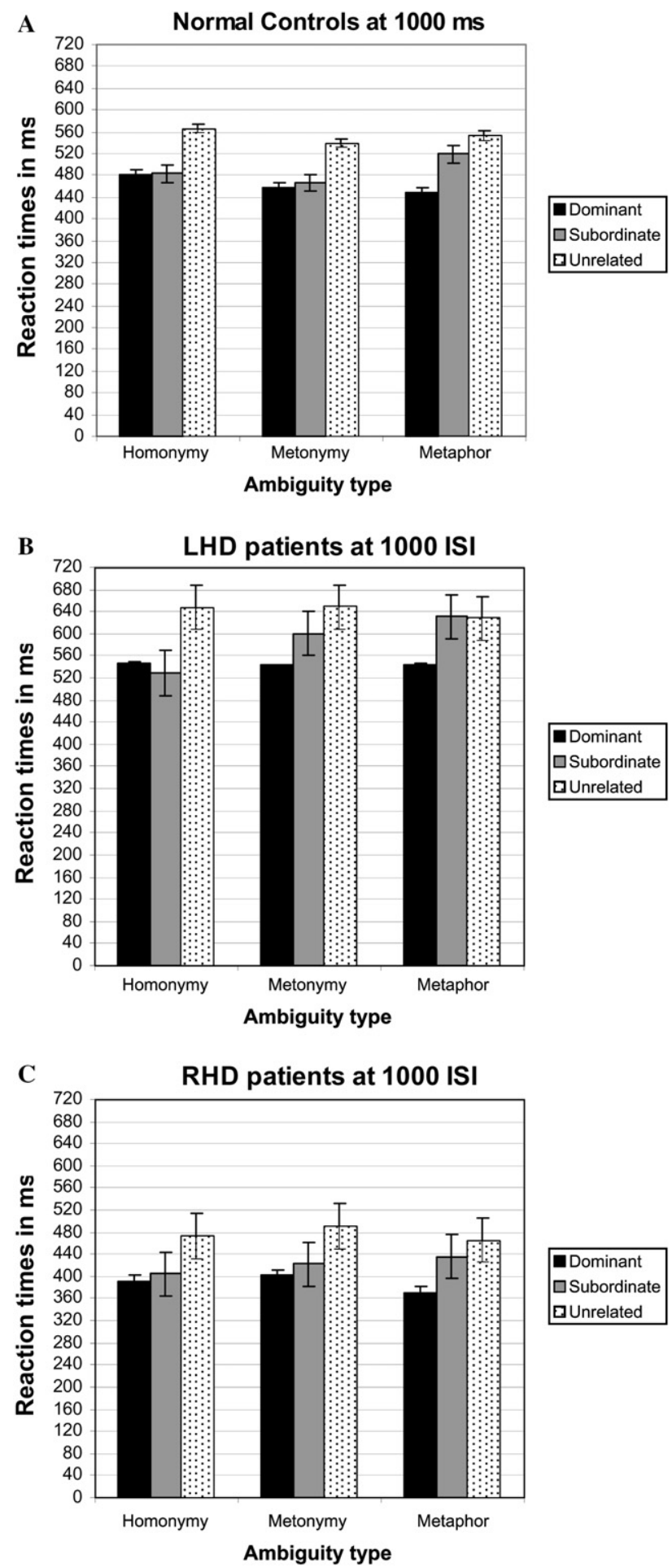

Fig. 2. Mean reaction times (and standard error) for all Groups at $1000 \mathrm{~ms}$ ISI for dominant related word targets (Dominant), subordinate related word targets (Subordinate), and control unrelated words targets (Unrelated) for each ambiguity type (Homonymy, Metonymy, and Metaphor). observed group effects were indeed representative of the performance of individual subjects. For homonymy, inspection of the individual data revealed that the group pattern of performance was evidenced by $70 \%$ of NC, $50 \%$ of LHD (while $30 \%$ inhibited subordinaterelated meanings), and $75 \%$ of RHD patients. For metonymy, the group pattern of facilitation was shown by $90 \%$ of NC, $50 \%$ of LHD (while $40 \%$ inhibited subordinate-related meanings), and $90 \%$ of RHD individuals. Although there were no significant interactions with Group, the performance of the LHD individuals was more variable than in the short ISI. It is possible that for some of the LHD patients, subordinate meanings were initially (at the short ISI) activated but activation was not sustained and decayed quickly (see also Grindrod \& Baum, 2003; Hagoort, 1993; Swaab, Brown, \& Hagoort, 1998). Crucially, however, the individual performance of the RHD patients mirrored that of the normal control subjects and was representative of the group performance. For the metaphor condition, as in the short ISI, the individual pattern of facilitation was substantially more variable, with only $40 \%$ of $\mathrm{NC}$ and LHD and $50 \%$ of RHD individuals exhibiting the group mean pattern; in contrast, $60 \%$ of $\mathrm{NC}, 40 \%$ of LHD, and $50 \%$ of RHD showed facilitation for both dominant- and subordinate-related meanings. However, as in the short ISI, there were no obvious characteristics that differentiated those individuals who conformed to the group pattern from those who did not, in any subject group.

\section{Discussion}

The present study aimed to investigate the effects of the strength of the semantic relations that hold between the different meanings (or senses) of three types of ambiguous words, (i.e., homonymy, metaphor, and metonymy). Based on evidence that both the left hemisphere (LH) and the right hemisphere (RH) contribute to the comprehension of semantic relations (e.g., Chiarello, 1991), patients with right-hemisphere damage (RHD) and left-hemisphere damage (LHD) as well as normal control subjects participated in auditory singleword priming tasks at both short $(100 \mathrm{~ms})$ and long $(1000 \mathrm{~ms})$ interstimulus intervals (ISI), in an attempt to test the "suppression deficit" (Tompkins \& Lehman, 1998) and the "coarse semantic coding" (Beeman et al., 1994) hypotheses. Furthermore, the use of a short and a long ISI provided the opportunity to explore both automatic and controlled semantic processing. Overall, the results provide evidence that the impaired brain (i.e., LHD non-fluent aphasic and RHD patients) can appreciate semantic relations and exhibit performance parallel to that of normal age-matched (i.e., older) control subjects at least at the single-word level. 
The results of the present study did not reveal significant group differences (see also Katz, 1988; Tompkins, 1990). The three subject groups (i.e., NC, LHD, and RHD) exhibited similar performance at both the short $(100 \mathrm{~ms})$ and the long $(1000 \mathrm{~ms})$ inter-stimulus intervals. In particular, dominant- and subordinate-related targets were processed significantly faster than unrelated control targets for the homonymy and metonymy conditions, whereas for the metaphor condition, only dominantrelated targets were facilitated (as reflected in group mean performance). These findings indicate that when ambiguous words are presented in isolation, LHD non-fluent aphasic patients as well as RHD patients show similar performance to normal age-matched control participants, activating both the dominant and subordinate meanings/senses of homonymous and metonymous words at the short interval and sustaining that activation until the long interval (i.e., until at least $1000 \mathrm{~ms}$ ). Similarly, for the metaphor condition, the two patient groups performed like the non-impaired control group, showing facilitation only for targets related to the dominant meaning of metaphorically ambiguous words at both the short and the long delays. Nevertheless, while the group data suggested that only the dominant meaning of metaphorically ambiguous words was facilitated at both ISIs, it must be noted that inspection of the individual data indicated that nearly half of the participants in each group activated both the dominant and subordinate meanings. Thus, the present findings provide evidence that the linguistic abilities of RHD and LHD non-fluent aphasic patients with respect to lexical ambiguity are relatively spared in the absence of context, mirroring the abilities of the age-matched normal control individuals.

It is of interest to note that the performance of the normal control individuals partly deviates from that reported in the literature. In particular, the findings for the short $(100 \mathrm{~ms})$ ISI, which is assumed to measure automatic processing, are largely consistent with previous studies showing that following a neutral context or in the absence of context, all meanings of homonymous words are initially activated (e.g., Seidenberg et al., 1982; Simpson \& Burgess, 1985; Tanenhaus et al., 1979). However, the sustained activation for both dominant and subordinate meanings of homonymous and metonymous words that was found at the longer $(1000 \mathrm{~ms})$ ISI (which is believed to assess more controlled processing) is in contradiction with the existing literature, according to which, at longer ISIs (after approximately $500 \mathrm{~ms}$ ), only dominant meanings show facilitation effects, whereas subordinate meanings are suppressed (e.g., Seidenberg et al., 1982; Tanenhaus et al., 1979). Nevertheless, it is important to note that the present study was conducted with older individuals, whereas the majority of previous work focused on the performance of young individuals (see also Kiran \& Thompson, 1998 for differences between young and older control subjects in pro- cessing homonymous words). It is conceivable that the mechanism that is responsible for suppressing "unwanted" meanings is compromised in older age. In fact, the findings for the normal control subjects of the present study are consistent with previous studies that compared the performance of young and older individuals in semantic processing and ambiguity resolution and found evidence that inhibition is compromised by old age (e.g., Faust, Balota, Duchek, Gernsbacher, \& Smith, 1997; Hasher \& Zacks, 1988; Kane, Hasher, Stoltzfus, Zacks, \& Connelly, 1994; Paul, 1996; experiment 1; but cf. Hopkins, Kellas, \& Paul, 1995; Lyons, Kellas, \& Martin, 1995; Paul, 1996; experiment 2). As a result of compromised inhibition, prolonged exhaustive meaning activation was found even at the longer ISI for the older normal control group. It is possible that an even longer ISI would be necessary for older individuals to suppress subordinate meanings when there are no contextual cues present to compel them to do so. Alternatively, it may be necessary to use tasks that demand meaning selection to clearly observe the effects of inhibition. For example, a recent study (Nievas \& Mari-Beffa, 2002) using a semantic judgment task with ambiguous words, in which young healthy subjects were asked to decide whether two words (e.g., "bank-money") are related, found facilitation for the selected meaning but inhibition for the unselected meaning. Nevertheless, although such paradigms would be useful to test controlled processes, they would be less able to tap automatic processing, which also constituted an objective of the present study.

As far as the brain-damaged patients are concerned, although previous priming studies (e.g., Grindrod \& Baum, 2003; Hagoort, 1993; Swaab et al., 1998; Tompkins et al., 1997, 2000) have demonstrated the effects of $\mathrm{LH}$ and $\mathrm{RH}$ lesions on the processing of ambiguous words, typically these studies have examined the ambiguous words in context. Therefore, it is not clear whether it was the presence of context that actually facilitated or inhibited the activation of the multiple meanings of ambiguous words in these patient populations. With respect to RHD patients, some early off-line studies indicated that they have problems appreciating the metaphoric meanings of words (e.g., Brownell, 1988; Brownell et al., 1984, 1990; Schmitzer et al., 1997; Winner \& Gardner, 1977). In addition, priming studies showed that RHD patients have problems inhibiting the contextually inappropriate meanings of homonymous words (Tompkins et al., 1997, 2000), and that they seem to rely mostly on frequency in the activation of homonymous word meanings, while access to context is initially disrupted (Grindrod \& Baum, 2003). However, there are not many studies that used single-word primes to investigate the processing abilities of brain-damaged individuals with respect to lexical ambiguity. Therefore, since all lexical ambiguity processing studies with RHD patients have either used context or off-line paradigms, it is not clear 
whether their problems with lexical ambiguity are due to processing deficits per se or to deficits appreciating and integrating context.

Our study provides evidence that when ambiguous words are presented out of sentential context, RHD patients exhibit similar performance to normal control individuals, indicating that at the single-word level RHD patients do not have a deficit accessing the meanings of ambiguous words. Interestingly, there is a single study that investigated the processing of ambiguous adjectives (e.g., "sharp") presented out of context in LHD and RHD patients (Tompkins, 1990). Although there are important differences between our study and this earlier study, the findings of the two studies are quite consistent. The first important difference is that Tompkins (1990) used the ambiguous adjectives as targets whereas their literal or metaphoric associates were used as primes. In our study, the ambiguous words were the primes whereas their dominant- and subordinate-meaning associates were the targets. Another very important difference between the two studies is the fact that Tompkins (1990) used only three ambiguous adjectives and had multiple repetitions of the materials which could lead to confounding effects. In our study, we made efforts to carefully control for repetition effects and to use a much larger sample of ambiguous words as well as a variety of different types of ambiguous words (i.e., homonymy, metonymy, and metaphor) to explore the strength of the semantic relations among the multiple meanings of ambiguous words. Nevertheless, despite these crucial differences in the design of the two studies, Tompkins (1990) also found that LHD and RHD individuals performed similar to normal controls in automatically accessing the alternate meanings of the ambiguous adjectives (see also Copland, Chenery, \& Murdoch, 2002; Metzler, 2001 for similar findings). The findings of our study provide additional evidence that, although RHD patients have been shown to have problems with lexical ambiguity processing in context, when ambiguous words are presented out of sentential context, RHD patients exhibit similar performance to normal control individuals. In addition, by clearly distinguishing between the different types of lexical ambiguity (i.e., homonymy, metonymy, and metaphor), the present study provides further insight to the abilities of RHD patients processing ambiguous words out of context. Thus, our findings (like those of Tompkins, 1990) point toward relatively spared processing after $\mathrm{RH}$ damage when ambiguous words are presented out of context.

Importantly, with respect to the RHD patients, the observed group effects were representative of the performance of individual subjects (see Section 4). Recall that the present group of RHD patients had unselected representative RH lesions affecting the function of the right cerebral hemisphere. Careful examination of the individual data did not reveal any differential patterns of per- formance due to differences in site of lesion. Thus, variations in type of lesion did not make obvious contributions to RHD patient performance.

Exploiting the particularities of three types of lexical ambiguity, namely homonymy, metaphor, and metonymy, the present study also set out to test the predictions of the "suppression deficit" (Tompkins \& Lehman, 1998) and the "coarse semantic coding" (Beeman et al., 1994) hypotheses that have been proposed to account for the deficits observed after RH damage. Recall that taking into consideration the linguistic distinctions of lexical ambiguity, the two hypotheses make different predictions about the performance of individuals with RHD. In particular, as described in Section 1, the strongest form of the "suppression deficit" hypothesis (Tompkins \& Lehman, 1998) would predict that individuals with RHD should be able to activate initially the multiple meanings of all types of lexical ambiguity while at longer delays they should be equally impaired at suppressing the alternative meanings/senses of all types of lexical ambiguity. Alternatively, the strongest form of the "coarse semantic coding" hypothesis (Beeman et al., 1994) would predict that individuals with RHD should be differentially impaired at accessing alternative meanings of homonymous but not metonymous words. Furthermore, the "coarse semantic coding" hypothesis also allowed predictions regarding the performance of the LHD patients, namely that they should be differentially impaired at accessing metonymous words and possibly the dominant meanings of homonymous and metaphorical words. Recall that until now support for the "suppression deficit" hypothesis primarily came from studies that used homonymous words in context (e.g., Tompkins et al., 1997, 2000), while support for the "coarse semantic coding" hypothesis mainly came from studies using the divided visual field methodology (e.g., Beeman et al., 1994; Chiarello et al., 1995). Our study used a uniform paradigm, namely homonymous, metonymous, and metaphorical ambiguous words presented out of context, to test some of the predictions of the two hypotheses.

The results of the present study did not provide support for the strongest predictions of the "coarse semantic coding" hypothesis as described herein. Recall that the "coarse semantic coding" hypothesis predicted that RHD patients would be differentially impaired at accessing the subordinate meanings of homonymous words but not metonymous words. Nevertheless, the present study showed that both dominant and subordinate meanings were activated and the performance of RHD patients mirrored that of older normal control participants. With respect to the "suppression deficit" hypothesis, recall that it predicted that RHD patients would be able to initially activate both dominant and subordinate meanings for each ambiguity type, while they would exhibit inefficient suppression of subordinate meanings at the longer delay. The present results did not support 
the second tenet, namely the suppression function, but they did provide evidence for the first tenet, namely exhaustive meaning activation. As mentioned previously, the RHD patients, as well as the LHD non-fluent aphasic patients, exhibited similar performance to the normal control group at both the short and long ISIs. In particular, they showed facilitation for both meanings/ senses of homonymous and metonymous words relative to unrelated control words, while for metaphorical words, there was facilitation of the primary meaning only. These results do not support the predictions in their entirety outlined for either the "suppression deficit" or the "coarse semantic coding" hypotheses, since, at least at the single-word level, the performance of the RHD, as well as the LHD, patients mirrored that of the older normal control individuals.

As already mentioned, the present findings are consistent with an earlier study by Tompkins (1990) that also found that LHD and RHD individuals showed similar performance to normal controls in automatically accessing alternate meanings of ambiguous adjectives, supporting only one tenet of the "suppression deficit" hypothesis, namely that automatic activation of multiple meanings is intact. Similarly, the present findings are also consistent with recent studies using the divided visual field methodology that have found evidence inconsistent with the "coarse semantic coding" hypothesis. In particular, findings from studies with lateralized presentation of ambiguous lexical items (Collins, 2002) suggest that the two hemispheres cooperate when generating alternate meanings of ambiguous words. Furthermore, it has been found that with central presentation of primes that exhibit various degrees (weak, moderate, and strong) of association to laterally presented targets, there is no interaction between visual field and association strength, suggesting that there is no difference between the hemispheres in activating more distant or closer associates of words (Coney, 2002). Thus, in concert with this recent divided visual field literature, the findings of the present study suggest that at the single-word level, both hemispheres seem to be capable of lexical-semantic processing. However, it is quite conceivable that incorporating the ambiguous words in context could help further test the predictions of the "coarse semantic coding" and "suppression deficit" hypotheses, since the presence of context might affect activation patterns. Furthermore, it is possible that using tasks that demand semantic integration (which is assumed to require controlled processing), such as semantic judgment tasks, would shed more light on the lexical-semantic abilities of the two cerebral hemispheres, further testing these two theories about $\mathrm{RH}$ language function/dysfunction.

With respect to LHD non-fluent aphasic patients, who also exhibited similar performance to the normal control group in our study, a number of studies with ambiguous words in context have shown that Broca's aphasic patients can indeed initially access alternate meanings of ambiguous words (e.g., Grindrod \& Baum, 2003; Hagoort, 1993; Milberg \& Blumstein, 1981; Swaab et al., 1998). An interesting finding of these studies was the fact that priming effects were shorter-lived in the aphasic patients than in the normal control subjects (see Hagoort, 1993). Thus, although aphasic patients initially access all meanings of ambiguous words (showing spared semantic representations), eventually (at longer delays) activation seems to decay. Hagoort (1993) argued that this fact could indicate either a faster decay in the automatic spread of activation, or an impairment (or delay) in lexical integration processes. In subsequent studies using ambiguous words in context, it was shown that Broca's aphasic patients have problems using context to select and integrate the appropriate meaning into the overall message representation of the contextual situation (Swaab et al., 1998). Thus, it was argued that LHD non-fluent aphasic patients do not have a deficit processing ambiguous words, but rather have a deficit in integrating ambiguous words in context (Swaab et al., 1998). In the present study, since ambiguous words were presented out of context, LHD non-fluent aphasic patients were not expected to have problems with contextual integration and were, therefore, expected to perform within normal limits (which they did). In this respect, the present findings are consistent with a previous study (Katz, 1988) which found that Broca's aphasics exhibit priming effects comparable to those of normal subjects in processing homonymous word pairs (e.g., "bankriver").

The results of the present study also shed some light on the hemispheric differences in processing lexical semantic relations. The assumption that the two hemispheres contribute differentially to the understanding of semantic relations is largely based on evidence from divided visual field studies with young normal individuals (e.g., Abernethy \& Coney, 1990, 1993, 1996; Atchley, Burgess et al., 1999; Chiarello et al., 1990; Chiarello \& Richards, 1992; Collins, 1999; Faust, Kravetz, \& Netzer, 2002; Koivisto, 1997, 1998a). However, it is important to investigate whether a focal lesion in the LH or the $\mathrm{RH}$ could disrupt the processing of ambiguous words in isolation. The present results (in parallel with those of Katz, 1988; Tompkins, 1990) indicate that, at least at the single-word level, LHD non-fluent aphasic individuals and RHD individuals exhibit normal performance at accessing the multiple meanings/senses of homonymous, metaphorical, and metonymous words. In that respect, the present results are consistent with recent findings from divided visual field studies (e.g., Chiarello et al., 2003; Collins, 2002; Coney, 2002; Koivisto, 1998b, 2000) that reveal the importance of interhemispheric cooperation in generating alternative meanings of ambiguous words and the similarities of the two cerebral hemispheres in activating more distant 
or closer associates of words. Not surprisingly, there is now additional evidence that even though the two hemispheres contribute differentially to the understanding of semantic relations, a lesion in one hemisphere does not completely disrupt processing ability at the single-word level (see also Katz, 1988; Tompkins, 1990; Tompkins \& Lehman, 1998).

Finally, another important finding of the present study was the fact that metaphors were treated differently from both homonymous and metonymous words by all three subject groups. This was evident both when looking at group performance (i.e., there were no facilitation effects for the secondary meaning/sense in the metaphor condition for any of the three subject groups), but also when looking at individual performance (i.e., there was greater individual variability for metaphors). In other words, although group performance exhibited facilitation for dominant meanings only, when looking at individual performance, almost $50 \%$ of the individuals showed facilitation for both dominant and subordinate meanings. However, facilitation for subordinate meanings never reached statistical significance, possibly indicating less reliable or less robust activation of these meanings. Thus, although subordinate meanings of metaphors were activated for some individuals, it seems that this activation was never strong enough or reliable enough in the absence of supporting context. These findings are consistent with the theoretical linguistics literature that holds that metaphorical senses tend to be inconsistent and unsystematic (Apresjan, 1974) and therefore more loosely related than the systematic and predictable metonymic senses. Metaphors are thought to have more distantly related semantic features that probably need a highly specific context situation to be triggered. As a result, the metaphorical sense could not be reliably activated out of context either at the short or the long ISI. An appropriate context situation seems to be necessary in order to reliably trigger access to the secondary, metaphorical senses of these words (but cf. Anaki et al., 1998). The present findings appear to be in disagreement with the findings of Anaki et al. (1998) who found facilitation for metaphorical meanings presented out of context. There are crucial differences, however, between the two studies that could contribute to the discordant results. To begin with, Anaki et al. (1998) used a divided visual field paradigm with young healthy adults, while older individuals participated in the present study. More importantly, however, there seem to be differences in the materials used. For example, Anaki et al. (1998) used phrases like "stinging-mosquito" (for the literal meaning) and "stinging-insult" (for the metaphorical meaning). Although the adjectival prime (i.e., "stinging") that carries the metaphorical meaning is presented out of context, when the target word is presented (i.e., "mosquito" or "insult"), a collocation or phrase is formed. It is conceivable that these two-word phrases provided more contextual information than the presentation of the simple associates (e.g., "spiceherb" or "spice-thrill") that were used in the present study, thus triggering more reliable access to the secondary, metaphorical meanings.

Nevertheless, as mentioned previously, it is likely that context critically affects the performance of braindamaged individuals either facilitating or inhibiting access to the alternative meanings/senses of ambiguous words (e.g., Grindrod \& Baum, 2003; Swaab et al., 1998; Tompkins et al., 1997, 2000) and, thus, context may also be necessary in order to observe possible processing differences between ambiguous words that have multiple unrelated meanings (i.e., homonymy) and ambiguous words that have multiple closely related senses (i.e., metonymy), in addition to assisting activation of the secondary meanings of metaphors. Finally, the use of context would also create demands for meaning selection, possibly providing a stronger test for suppression effects of contextually inappropriate meanings.

In conclusion, the present study used three subject groups (i.e., LHD, RHD, and NC) to investigate lexical ambiguity processing out of context in an attempt to test the "suppression deficit" and the "coarse semantic coding" hypotheses. The three subject groups exhibited similar performance, indicating that at least at the singleword level patients with $\mathrm{LH}$ or RH damage can access the multiple meanings of ambiguous words and exhibit processing abilities comparable to those of the older normal control group, in contrast to the predictions of both hypotheses. More specifically, it was found that the multiple meanings or senses of homonymous and metonymous words can be triggered and accessed outside of context, whereas for metaphorical words, context seems to mediate access to secondary metaphorical meanings. By using different types of ambiguous words out of context, the present study provides evidence that the impaired brain can appreciate semantic relations and exhibit performance comparable to normal at the singleword level.

\section{Acknowledgments}

The research reported here is part of the doctoral dissertation of the first author. This research was supported by a McGill Majors Fellowship and a Studentship from the Faculty of Medicine, McGill University to the first author and by a grant from the Fonds pour la Formation de Chercheurs et l'Aide à la Recherche (FCAR, now FRNTQ) to the second author. We thank the patients and normal control subjects who participated in the study. We also thank the editor and the reviewers for their useful comments and suggestions. 


\section{Appendix}

Experimental stimuli for the single-word priming study

\begin{tabular}{llll}
\hline Prime & Target & & \\
\cline { 2 - 4 } & Dominant & Subordinate & Unrelated Control \\
\hline Homonymy & & & \\
ball & round & dance & battle \\
count & eighty & duke & rake \\
file & drawer & carpenter & trumpet \\
march & april & soldiers & portion \\
park & bench & vehicle & context \\
yard & grass & mile & sin \\
drill & machine & practice & marriage \\
fan & breeze & sport & tile \\
mint & candy & coin & ruin \\
pen & ink & crib & dip \\
port & dock & brandy & lotion \\
toll & fee & bell & flame \\
bluff & fake & cliff & button \\
bolt & screw & jump & joke \\
foil & silver & fool & ocean \\
mole & dig & wart & tide \\
perch & branch & fish & crime \\
punch & fist & fruit & shock
\end{tabular}

Metaphor

\begin{tabular}{|c|c|c|c|}
\hline arm & wrist & couch & reef \\
\hline lip & chap & rim & swamp \\
\hline mouth & eat & flow & rifle \\
\hline neck & throat & narrow & motor \\
\hline shoulder & blade & sleeve & ballot \\
\hline tongue & lick & laces & broom \\
\hline chicken & hen & scared & soap \\
\hline cow & milk & fat & lake \\
\hline fox & hound & sly & spoon \\
\hline parrot & pirate & mimic & comet \\
\hline pig & mud & dirty & clerk \\
\hline worm & snail & slimy & coupon \\
\hline doll & toy & cute & hook \\
\hline gem & stone & unique & smile \\
\hline nucleus & electron & boss & motel \\
\hline pillar & column & model & chapter \\
\hline spice & herb & thrill & comb \\
\hline star & universe & famous & coffee \\
\hline \multicolumn{4}{|c|}{ Metonymy } \\
\hline bag & luggage & garbage & pillow \\
\hline barrel & keg & pickles & gust \\
\hline bottle & cork & alcohol & ghost \\
\hline basket & weave & laundry & dove \\
\hline cup & bowl & tea & fog \\
\hline glass & crystal & juice & thread \\
\hline lemon & lime & squeeze & silk \\
\hline maple & leaf & syrup & choir \\
\hline onion & pepper & salad & cement \\
\hline pine & tree & smell & trend \\
\hline potato & spud & mash & claw \\
\hline rabbit & hop & stew & chalk \\
\hline alley & lane & cat & shirt \\
\hline ena & stadium & concert & carbon \\
\hline ge & metal & animal & credit \\
\hline chimney & brick & sweep & nurse \\
\hline pipe & tube & smoke & tape \\
\hline theater & screen & drama & pilot \\
\hline
\end{tabular}

\section{References}

Abernethy, M., \& Coney, J. (1990). Semantic and phonemic priming in the cerebral hemispheres. Neuropsychologia, 28, 933-945.

Abernethy, M., \& Coney, J. (1993). Associative priming in the hemispheres as a function of SOA. Neuropsychologia, 31, 1397-1410.

Abernethy, M., \& Coney, J. (1996). Semantic category priming in the left cerebral hemisphere. Neuropsychologia, 34, 339-350.

Anaki, D., Faust, M., \& Kravetz, S. (1998). Cerebral hemispheric asymmetries in processing lexical metaphors. Neuropsychologia, 36, 691-700.

Apresjan, J. (1974). Regular polysemy. Linguistics, 142, 5-32.

Atchley, R. A., Burgess, C., \& Keeney, M. (1999). The effect of time course and context on the facilitation of semantic features in the cerebral hemispheres. Neuropsychology, 13, 389-403.

Atchley, R. A., Keeney, M., \& Burgess, C. (1999). Cerebral hemispheric mechanisms linking ambiguous word meaning retrieval and creativity. Brain and Cognition, 40, 479-499.

Azuma, T., \& Van Orden, G. C. (1997). Why SAFE is better than FAST: The relatedness of a word's meanings affects lexical decision times. Journal of Memory and Language, 36, 484-504.

Beeman, M. (1993). Semantic processing in the right hemisphere may contribute to drawing inferences from discourse. Brain and Language, 44, 80-120.

Beeman, M. (1998). Coarse semantic coding and discourse comprehension. In M. Beeman \& C. Chiarello (Eds.), Right Hemisphere Language Comprehension (pp. 255-284). Mahwah, NJ: Lawrence Erlbaum Associates.

Beeman, M., Friedman, R. B., Grafman, J., Perez, E., Diamond, S., \& Lindsay, M. B. (1994). Summation priming and coarse semantic coding in the right hemisphere. Journal of Cognitive Neuroscience, 6, 26-45.

Brownell, H. H. (1988). Appreciation of metaphoric and connotative word meaning by brain-damaged patients. In C. Chiarello (Ed.), Right hemisphere contributions to lexical semantics (pp. 19-31). Berlin: Springer

Brownell, H. H., Potter, H. H., Michelow, D., \& Gardner, H. (1984). Sensitivity to lexical denotation and connotation in brain-damaged patients: A double dissociation. Brain and Language, 22, 253-265.

Brownell, H. H., Simpson, T. L., Bihrle, A. M., Potter, H. H., \& Gardner, H. (1990). Appreciation of metaphoric alternative word meanings by left and right brain-damaged patients. Neuropsychologia, $28,375-383$.

Burgess, C., \& Lund, K. (1998). Modeling cerebral asymmetries in high-dimensional space. In M. Beeman \& C. Chiarello (Eds.), Right hemisphere language comprehension (pp. 215-244). Mahwah, NJ: Lawrence Erlbaum Associates.

Burgess, C., \& Simpson, G. B. (1988). Cerebral hemispheric mechanisms in the retrieval of ambiguous word meanings. Brain and Language, 33, 86-103.

Caplan, D. (1992). Language: Structure, process, and disorders. Cambridge, MA: MIT Press.

Chiarello, C. (1991). Interpretation of word meanings by the cerebral hemispheres: one is not enough. In P. J. Schwanenflugel (Ed.), The psychology of word meanings (pp. 251-278). Mahwah, NJ: Lawrence Erlbaum Associates.

Chiarello, C., Burgess, C., Richards, L., \& Pollock, A. (1990). Semantic and associative priming in the cerebral hemispheres: Some words do, some words don't ... sometimes, some places. Brain and Language, 38, 75-104.

Chiarello, C., Liu, S., Shears, C., Quan, N., \& Kacinik, N. (2003). Priming of strong semantic relations in the left and right visual fields: A time-course investigation. Neuropsychologia, 41, 721-732.

Chiarello, C., Maxfield, L., \& Kahan, T. (1995). Initial right hemisphere activation of subordinate word meanings is not due to homotopic callosal inhibition. Psychonomic Bulletin \& Review, 2, 375-380. 
Chiarello, C., \& Richards, L. (1992). Another look at categorical priming in the cerebral hemispheres. Neuropsychologia, 30, 381392.

Collins, M. (1999). Differences in semantic category priming in the left and right cerebral hemispheres under automatic and controlled priming conditions. Neuropsychologia, 37, 1071-1088.

Collins, M. (2002). Interhemispheric communication via direct connections for alternative meanings of ambiguous words. Brain and Language, 80, 77-96.

Coney, J. (2002). The effect of associative strength on priming in the cerebral hemispheres. Brain and Cognition, 50, 234-241.

Copland, D. A., Chenery, H. J., \& Murdoch, B. E. (2002). Hemispheric contributions to lexical ambiguity resolution: Evidence from individuals with complex language impairment following left-hemisphere lesions. Brain and Language, 81, 131-143.

Cruse, D. A. (1986). Lexical semantics. CUP.

Duffy, S. A., Morris, R. K., \& Rayner, K. (1988). Lexical ambiguity and fixation times in reading. Journal of Memory and Language, 27, 429-446.

Durkin, K., \& Manning, J. (1989). Polysemy and the subjective lexicon: Semantic relatedness and the salience of intraword senses. Journal of Psycholinguistic Research, 18, 577-612.

Faust, M. E., Balota, D. A., Duchek, J. M., Gernsbacher, M. A., \& Smith, S. (1997). Inhibitory control during sentence comprehension in individuals with dementia of the Alzheimer type. Brain and Language, $57,225-253$.

Faust, M. E., \& Gernsbacher, M. A. (1996). Cerebral mechanisms for suppression of inappropriate information during sentence comprehension. Brain and Language, 53, 234-259.

Faust, M., Kravetz, S., \& Netzer, E. (2002). Effects of sentential context on the processing of unambiguous words by the two cerebral hemispheres. Brain and Language, 80, 438-448.

Fodor, J. A. (1983). The modularity of mind. Cambridge, MA: MIT Press.

Folstein, M. F., Folstein, S. E., \& McHugh, P. R. (1975). "Mini-mental state": A practical method for grading the cognitive state of patients for the clinician. Journal of Psychiatric Research, 12, 189198.

Francis, W. N., \& Kucera, H. (1982). Frequency analysis of English usage: Lexicon and grammar. Boston: Houghton Mifflin.

Frazier, L., \& Rayner, K. (1990). Taking on semantic commitments: Processing multiple meanings vs. multiple senses. Journal of Memory and Language, 29, 181-200.

Gilhooly, K. J., \& Logie, R. H. (1980). Meaning-dependent ratings of imagery, age of acquisition, familiarity, and concreteness for 387 ambiguous words. Behavior Research Methods and Instrumentation, $12,428-450$.

Goodglass, H., Kaplan, E., \& Barresi, B. (2001). The assessment of aphasia and related disorders. Lippincott: Williams and Wilkins.

Grindrod, C. M., \& Baum, S. R. (2003). Sensitivity to local sentence context information in lexical ambiguity resolution: Evidence from left- and right-hemisphere-damaged individuals. Brain and Language, $85,503-523$.

Hagoort, P. (1993). Impairments of lexical-semantic processing in aphasia: Evidence from the processing of lexical ambiguities. Brain and Language, 45, 189-232.

Hagoort, P., Brown, C. M., \& Swaab, T. Y. (1996). Lexical-semantic event-related potential effects in patients with left hemisphere lesions and aphasia, and patients with right hemisphere lesions without aphasia. Brain, 119, 627-649.

Hasher, L., \& Zacks, R. T. (1988). Working memory, comprehension and aging: A review and a new view. In G. G. Bower (Ed.), The psychology of learning and motivation (Vol. 22, pp. 193-225). San Diego, CA: Academic Press.

Hopkins, K. E., Kellas, G., \& Paul, S. T. (1995). Scope of word meaning activation during sentence processing by young and older adults. Experimental Aging Research, 21, 123-142.
Kane, J. K., Hasher, L., Stoltzfus, E. R., Zacks, R. T., \& Connelly, S. L. (1994). Inhibitory attentional mechanisms and aging. Psychology and Aging, 9, 103-112.

Kaplan, E., Goodglass, H., \& Weintraub, S. (1983). Boston Naming Test. Philadelphia, PA: Lea and Febiger.

Katz, W. F. (1988). An investigation of lexical ambiguity in Broca's aphasics using an auditory lexical priming technique. Neuropsychologia, 26, 747-752.

Klein, D. E., \& Murphy, G. L. (2001). The representation of polysemous words. Journal of Memory and Language, 45, 259-282.

Klein, D. E., \& Murphy, G. L. (2002). Paper has been my ruin: Conceptual relations of polysemous senses. Journal of Memory and Language, 47, 548-570.

Klepousniotou, E. (2002). The processing of lexical ambiguity: Homonymy and polysemy in the mental lexicon. Brain and Language, 81, 205-223.

Kiran, S., \& Thompson, C. K. (1998). Time course of activation of polysemous word meanings in young and elderly individuals. Brain and Language, 65, 127-130.

Koivisto, M. (1997). Time course of semantic activation in the cerebral hemispheres. Neuropsychologia, 35, 497-504.

Koivisto, M. (1998a). Categorical priming in the cerebral hemispheres: Automatic in the left hemisphere, post-lexical in the right hemisphere. Neuropsychologia, 36, 661-668.

Koivisto, M. (1998b). Backward priming and postlexical processing in the right hemisphere. Laterality, 3, 21-40.

Koivisto, M. (2000). Hemispheric asymmetries in activation and integration of categorical information. Laterality, 5, 1-21.

Lyons, J. (1977). Semantics. Vol. 1-2. CUP.

Lyons, K. E., Kellas, G., \& Martin, M. (1995). Inter- and intra-individual differences in semantic priming among young and older adults. Experimental Aging Research, 21, 221-237.

Mertus, J. (2000). Brown lab interactive speech system [Computer software ]. Providence, RI: Brown University.

Metzler, C. (2001). Effects of left frontal lesions on the selection of context-appropriate meanings. Neuropsychology, 15, 315-328.

Milberg, W., \& Blumstein, S. E. (1981). Lexical decision and aphasia: Evidence for semantic processing. Brain and Language, 14, 371-385.

Milberg, W., Blumstein, S. E., \& Dworetzky, B. (1987). Processing of lexical ambiguities in aphasia. Brain and Language, 31, 138-150.

Nelson, D. L., McEvoy, C. L., \& Schreiber, T. A. (1998). The University of Florida word association, rhyme and word fragment norms. Available from http://www.usf.edu/FreeAssociation/.

Nelson, D. L., McEvoy, C. L., Walling, J. R., \& Wheeler, J. W., Jr. (1980). The University of South Florida homograph norms. Behavior Research Methods and Instrumentation, 12, 16-37.

Nievas, F., \& Mari-Beffa, P. (2002). Negative priming from the nonselected meaning of the homograph. British Journal of Psychology, 93, 47-66.

Nunberg, G. (1979). The non-uniqueness of semantic solutions: Polysemy. Linguistics and Philosophy, 3, 143-184.

Paul, S. T. (1996). Search for semantic inhibition failure during sentence comprehension by younger and older adults. Psychology and Aging, 11, 10-20.

Pustejovsky, J. (1995). The Generative Lexicon. Cambridge, MA: MIT Press.

Rayner, K., Binder, K. S., \& Duffy, S. A. (1999). Contextual strength and the subordinate bias effect: Comment on Martin, Vu, Kellas, and Metcalf. The Quarterly Journal of Experimental Psychology, 52, 841-852.

Rayner, K., \& Frazier, L. (1989). Selection mechanisms in reading lexically ambiguous words. Journal of Experimental Psychology: Learning, Memory and Cognition, 15, 779-790.

Rayner, K., Pacht, J. M., \& Duffy, S. A. (1994). Effects of prior encounter and global discourse bias on the processing of lexically ambiguous words: Evidence from eye fixations. Journal of Memory and Language, 33, 527-544. 
Rodd, J., Gaskell, G., \& Marslen-Wilson, W. (2002). Making sense of semantic ambiguity: Semantic competition in lexical access. Journal of Memory and Language, 46, 245-266.

Schmitzer, A. B., Strauss, M., \& DeMarco, S. (1997). Contextual influences on comprehension of multiple-meaning words by right hemisphere brain-damaged and non-brain-damaged adults. Aphasiology, 11, 447-459.

Schreuder, R., \& Flores d' Arcais, G. B. (1989). Psycholinguistic issues in the lexical representation of meaning. In W. Marslen-Wilson (Ed.), Lexical representation and process (pp. 409-436). Cambridge, MA: MIT Press.

Seidenberg, M. S., Tanenhaus, M. K., Leiman, J. M., \& Bienkowski, M. (1982). Automatic access of the meanings of ambiguous words in context: Some limitations of knowledge-based processing. Cognitive Psychology, 14, 489-537.

Simpson, G. B. (1994). Context and the processing of ambiguous words. In M. A. Gernsbacher (Ed.), Handbook of psycholinguistics. San Diego: Academic Press.

Simpson, G. B., \& Burgess, C. (1985). Activation and selection processes in the recognition of ambiguous words. Journal of Experimental Psychology: Human Perception and Performance, 11, 28-39.

Simpson, G. B., \& Krueger, M. A. (1991). Selective access of homograph meanings in sentence context. Journal of Memory and Language, 30, 627-643.

Stevens, J. (1996). Applied multivariate statistics for the social sciences (3rd ed.). Mahwah, NJ: Lawrence Erlbaum Associates.

Swaab, T. Y., Brown, C., \& Hagoort, P. (1998). Understanding ambiguous words in sentence contexts: Electrophysiological evidence for delayed contextual selection in Broca's aphasia. Neuropsychologia, $36,737-761$.

Swinney, D. A. (1979). Lexical access during sentence comprehension: (Re)consideration of context effects. Journal of Verbal Learning and Verbal Behavior, 18, 645-659.

Swinney, D. A. (1991). The resolution of indeterminacy during language comprehension: Perspectives on modularity in lexical, structural and pragmatic process. In G. B. Simpson (Ed.), Understanding word and sentence (pp. 367-385). Amsterdam: Elsevier Science Publishers.
Tabossi, P. (1988). Accessing lexical ambiguity in different types of sentential contexts. Journal of Memory and Language, 27, 324-340.

Tanenhaus, M. K., Leiman, J. M., \& Seidenberg, M. S. (1979). Evidence for multiple stages in the processing of ambiguous words in syntactic contexts. Journal of Verbal Learning and Verbal Behavior, 18, $427-440$

Tompkins, C. A. (1990). Knowledge and strategies for processing lexical metaphor after right or left hemisphere brain damage. Journal of Speech and Hearing Research, 33, 307-316.

Tompkins, C. A., Baumgaertner, A., Lehman, M. T., \& Fassbinder, W. (2000). Mechanisms of discourse comprehension impairment after right hemisphere brain damage: Suppression in lexical ambiguity resolution. Journal of Speech, Language, and Hearing Research, 43 , 62-78.

Tompkins, C. A., Baumgaertner, A., Lehman, M. T., \& Fossett, T. R. D. (1997). Suppression and discourse comprehension in right braindamaged adults: A preliminary report. Aphasiology, 11, 505-519.

Tompkins, C. A., \& Lehman, M. T. (1998). Interpreting intended meanings after right hemisphere brain damage: An analysis of evidence, potential accounts, and clinical implications. Topics in Stroke Rehabilitation, 5, 29-47.

Twilley, L. C., Dixon, P., Taylor, D., \& Clark, K. (1994). University of Alberta norms of relative meaning frequency for 566 homographs. Memory \& Cognition, 22, 111-126.

Wechsler, D. W. (1987). Wechsler memory scale revised. San Antonio: Harcourt, Brace and Jovanovich.

Wiig, E. H., \& Secord, W. (1987). Test of language competenceexpanded edition. San Antonio, TX: Harcourt, Brace and Jovanovich.

Williams, J. N. (1992). Processing polysemous words in context: Evidence for interrelated meanings. Journal of Psycholinguistic Research, 21, 193-218.

Wilson, B., Cockburn, J., \& Halligan, P. (1987). Behavioural inattention test. Titchfield, UK: Thames Valley Test Company.

Winner, E., \& Gardner, H. (1977). The comprehension of metaphor in brain-damaged patients. Brain, 100, 719-727.

Yates, J. (1978). Priming dominant and unusual senses of ambiguous words. Memory \& Cognition, 6, 636-643. 